\title{
ANTrosoles ARQUeOlÓgICOS DEL BAJO RÍO URUGUAY: UNA APROXIMACIÓN GEOARQUEOLÓGICA A LOS PROCESOS DE FORMACIÓN DEL SITIO ISLA DEL VizCAÍNO 1 (DEPARTAMENTO RÍo NEGRO - URUGUAY)
}

\author{
Noelia Bortolotto ${ }^{\mathrm{a}}$, Laura del Puerto ${ }^{\mathrm{b}}$, Andrés Gascue ${ }^{\mathrm{c}}$, Daniel Loponte ${ }^{\mathrm{d}}$, \\ Alejandro Acosta ${ }^{\mathrm{e}}$, Germán Azcune ${ }^{\mathrm{f}}$, Hugo Inda ${ }^{\mathrm{g}}$, Marcelo Fleitas ${ }^{\mathrm{h}}$ y Mercedes Rivas ${ }^{\mathrm{i}}$
}

\begin{abstract}
Resumen
En este trabajo se presentan los resultados del análisis de suelos antropogénicos arqueológicos del sitio Isla del Vizcaino 1 (Delta del Río Negro, Uruguay), ubicado sobre un albardón fluvial y fechado en circa 1500 años AP. A través de un diseño mensurativo comparativo (dentro y fuera del sitio) se buscó caracterizar las modificaciones generadas por las poblaciones humanas prehispánicas que allí habitaron sobre su entorno fisico y biológico, en términos de su rol como factor pedogenético, y al mismo tiempo aportar datos que permitan discutir con una base sólida los procesos de formación de sitios en elevaciones de la región litoral.
\end{abstract}

Los resultados alcanzados mediante análisis granulométricos, composicionales y geoquímicos muestran claras diferencias entre los suelos antropogénicos arqueológicos y los suelos naturales adyacentes, evidenciadas principalmente en la presencia de material cultural y mayores contenidos de materia orgánica y fósforo en los primeros. A partir de los datos generados se identificó la presencia de dos horizontes de un antrosol metagenético (HAM), es decir, de un suelo compuesto por material alterado (y no transportado) por el hombre, caracterizado como antroarenosol cuarzo feldespático. Esta alteración del suelo, vinculada a actividades domésticas y rituales en este sitio, evidencia el rol del hombre prehispánico como agente pedogenético y como actor activo en la modelación del paisaje.

Palabras clave: litoral rio Uruguay, geoarqueología, suelos antrópicos.

a https://orcid.org/0000-0002-4076-7703. Centro Universitario Regional del Este (CURE), Universidad de la República (UdelaR); Instituto Nacional de Antropología y Pensamiento Latinoamericano (INAPL). noeliabortolotto@gmail.com

b https://orcid.org/0000-0003-2003-9263. Centro Universitario Regional del Este (CURE), Universidad de la República (UdelaR). lau2phy@yahoo.com

c https://orcid.org/0000-0002-4138-9951. Centro Universitario Regional del Este (CURE), Universidad de la República (UdelaR). andresgascue@gmail.com

d https://orcid.org/0000-0002-3826-5595. Consejo Nacional de Investigaciones Científicas y Técnicas (CONICET); Instituto Nacional de Antropología y Pensamiento Latinoamericano (INAPL). dashtown@gmail.com

e https://orcid.org/0000-0003-4963-1703. Consejo Nacional de Investigaciones Científicas y Técnicas (CONICET); Instituto Nacional de Antropología y Pensamiento Latinoamericano (INAPL). acostaalejandroalberto@gmail.com

f https://orcid.org/0000-0003-3016-9352. Centro Universitario Regional del Este (CURE), Universidad de la República (UdelaR). german.azcune@gmail.com

$\mathrm{g}$ https://orcid.org/0000-0003-1955-7821. Centro Universitario Regional del Este (CURE), Universidad de la República (UdelaR). hugoboss@paysandu.com

h Facultad de Humanidades y Ciencias de la Educación (FHCE), Universidad de la República (UdelaR). mhorusf@ gmail.com

i https://orcid.org/0000-0003-2704-6407. Centro Universitario Regional del Este (CURE), Universidad de la República (UdelaR).mechirivas@gmail.com 


\section{Abstract \\ ARCHAEOLOGICAL ANTHROSOLS OF THE LOWER URUGUAY RIVER: A GEOARCHAEOLOGICAL APPROACH TO THE FORMATION PROCESSES OF THE ISLA DE VIZCAÍNO 1 ARCHAEOLOGICAL SITE (RÍO NEGRO DEPARTMENT - URUGUAY)}

This work presents the results of the analysis of archaeological anthropogenic soils analysis of Isla de Vizcaino 1 site (Rio Negro Department, Uruguay), located on a riverbank and dated around 1500 years BP. Through a comparative measurement design (inside and outside the site), we sought to characterize the modifications generated by pre-Hispanic human populations that inhabited these environments, in terms of their role as a pedogenetic agent, and at the same time provide data that, with a solid basis, allow discussing the formation processes of elevated sites from the littoral region.

The results achieved through granulometric, compositional and geochemical analyzes showed clear differences between archaeological anthropogenic soils and adjacent natural soils, evidenced mainly by the presence of cultural material and higher organic matter and phosphorous content in the first. From generated data, the presence of two horizons of a metagenetic anthrosol (HAM) were identified, that is, a soil composed of altered material (and not transported) by human agency, characterized as quartz-feldspathic anthrosand. This alteration of the soil, linked to domestic and ritual activities in this site, highlighted the role of pre-Hispanic inhabitants as a pedogenetic agent and as an active actor in landscape modelling and environmental engineering.

Keywords: Littoral Uruguay River; Geoarchaeology; Anthropic soils.

\section{Introducción}

Las poblaciones prehispánicas que habitaron la cuenca baja de los ríos Paraná y Uruguay durante el Holoceno Tardío, han sido enmarcadas en un proceso de complejización cultural basado en la presencia de indicadores como: baja movilidad residencial, producción de excedentes económicos y consumo diferido, intensificación y generación de parches de recursos antrópicamente generados, especialización tecno económica, modificación del paisaje, procesos de intercambio y el establecimiento de cementerios utilizados por generaciones (Loponte et al. 2006; Loponte 2008; Gascue 2009; Acosta y Loponte, 2013; Loponte y Acosta 2016; Loponte et al. 2016a; Bortolotto 2018; Mazza et al. 2018; Gascue et al. 2019a). Algunos autores han considerado que la construcción de elevaciones artificiales son también una evidencia del surgimiento de la complejidad cultural (Bonomo et al. 2011a y b), mientras que otros (Gaspary 1950; Ceruti y González 2007; Loponte et al. 2016b) los consideran un epifenómeno intrínseco de los sistemas residenciales locales de baja movilidad, destinados a evitar el anegamiento de asentamientos centrales. En los antecedentes bibliográficos de los sitios de la isla del Vizcaíno se observan elementos vinculados con este grado de complejidad cultural señalado anteriormente; sin embargo, los aspectos relacionados con los procesos de formación y elevación de los mismos no han sido suficientemente investigados.

En general, la literatura arqueológica de la región ha abordado la génesis de sitios en elevación del litoral desde distintas perspectivas. En este sentido, las hipótesis van desde la génesis antrópica (Lista 1877; Figueira, 1892; Torres 1911; Arredondo 1927; Maruca Sosa 1957; Bonomo et al. 2011a); la ocupación de elevaciones naturales con descarte de desechos in situ que produce el aumento en altura de los sitios arqueológicos (Torres 1911; Outes 1912; Frenguelli y Aparicio 1923; Fontana 1928; Greslebin 1931; Lothrop 1932; Aparicio 1937; González 1947; Gaspary 1950; Nóbile et al. 1999) y una combinación de las anteriores (Fontana 1928; Greslebin 1931; Gaspary 1950; Lafón 1971; Bonomo et al. 2011b; Loponte et al. 2016b). De esta manera, la génesis de las elevaciones ocupadas puede tener diferentes orígenes; lo importante dentro de un programa de investigación es poder sustentar las posturas con evidencias científicas.

Los sitios arqueológicos de la margen izquierda (uruguaya) del bajo río Uruguay presentan registros de explotación de recursos acuáticos y terrestres, manufactura y uso de alfarería 
y artefactos líticos tallados y picados/pulidos. Los mismos se ubican mayoritariamente en formas naturalmente elevadas del paisaje identificados como cordones arenosos y albardones. $\mathrm{Al}$ respecto, trabajos anteriores con perspectiva regional, han seńalado la ausencia de estructuras construidas en el área reseñada (Boretto et al. 1973; Gascue et al. 2019a). Independientemente de ello, existen similitudes tecnológicas, estilísticas y económicas que permiten relacionar las ocupaciones en la margen oriental del bajo río Uruguay con distintas unidades arqueológicas correspondientes a grupos cazadores-recolectores complejos identificadas en la margen derecha del río Uruguay y en el Paraná medio e inferior. Por otra parte, a partir de estilos cerámicos corrugados y pintados también se han identificado en el área ocupaciones de grupos guaraníes (Figueira 1892, Maruca Sosa 1957; López Mazz y López 2020). Estas se manifiestan en sitios exclusivamente guaraní (Gascue y Bortolotto 2016), pero en el mayor de los casos estas evidencias se encuentran asociadas a contextos de cazadores-recolectores (Gascue et al. 2019a).

En este trabajo y desde una perspectiva geoarqueológica, se aporta información tendiente a establecer los procesos de formación del sitio elevado Isla de Vizcaíno 1, localizado en el delta del río Negro, sobre la margen izquierda del riacho Vizcaíno. El objetivo final ha sido contribuir al debate actual sobre la interacción humano-ambiental durante el Holoceno Tardío en la región y sus implicancias socio-culturales.

\section{Características ambientales generales del área de estudio}

En términos generales, el tramo inferior del río Uruguay se extiende desde Salto Chico (frente a las ciudades de Salto y Concordia) hasta Punta Gorda (departamento de Colonia). Sus principales afluentes son los ríos Gualeguaychú, por la margen derecha y Daymán, Queguay, Negro y San Salvador por la margen izquierda. A ambas márgenes presenta relieves planos, dominados por la planicie fluvial, con desarrollo de albardones costeros y cordones arenosos, con períodos de inundación parcial y dos crecidas anuales (Palacios 2002). Se desarrolla aquí una variada flora y fauna, propia de las ecorregiones Pampeanas, del Espinal y Delta e islas del Paraná (Cabrera y Willink 1980; Burkart et al. 1999).

Geológicamente, la isla del Vizcaíno presenta una agrupación muy heterogénea de materiales sedimentarios que se acumularon en épocas recientes por acción fluvial. La carta geológica (Bossi et al. 1998) menciona que las planicies mareales están asociadas a ingresiones, que alcanzaron zonas en cotas de +5 metros. La planicie se caracteriza por la presencia de albardones costeros, que son rebasados por el crecimiento de las aguas durante las inundaciones. Hacia el centro de la isla dominan los gleysoles háplicos melánicos, gley húmicos, fluviosoles heterotexturales melánicos, vertisoles háplicos y grumosoles. Todos presentan un horizonte superior negro, franco arcillo limoso, de alta fertilidad y drenaje pobre (CONEAT 1979).

\section{Hipótesis sobre procesos de formación de sitios del área}

Desde fines de siglo XIX y principios del XX, distintos investigadores en la región mencionan la presencia de túmulos ${ }^{1}$ en el litoral uruguayo haciendo referencia a estructuras monticulares construidas que se caracterizaban por contener restos óseos humanos. De estas últimas, las más frecuentemente referidas para la zona son: túmulo/s de la isla del Vizcaíno (Arredondo 1927; Figueira 1892; Maeso 1977), túmulo de la Isla del Naranjo (Arredondo 1927), túmulo de Punta Chaparro (Fontana 1928, 1930), túmulo de la Blanqueada (de Freitas 1942, 1953; Maeso 1977) y túmulos de Cañada Saldańa (o Colonia Concordia según el autor; Teisseire 1927; Maruca Sosa 1957; Díaz et al. 1980). En todos los casos los autores coinciden en el carácter antropogénico de estas elevaciones; por ejemplo, Fontana especifica que el túmulo de Punta Chaparro habría sido «formado por distintas tierras acumuladas por la mano del hombre sobre las arenas de un albardón, 
que a su vez descansan sobre la capa de arcilla de la playa» (Fontana 1930: 165-166). Para Cañada Saldaña, Maruca Sosa (1957: 175) señala que «(...) Fue construido totalmente, transportando en cueros de animales, tierras y arenas de las adyacencias, depositándolas a un costado del bańado». Posteriormente, Díaz y colaboradores (1980) agregan que no se aprecian estratos diferenciados en este yacimiento.

Según Farías (2005), en el sitio La Blanqueada se observa la presencia de una estratigrafía «estructurada por agregación laminar, con estratos muy finos, típicos de la acreción de limos de desborde» (Farías 2005: 68) y lo interpreta como «la expresión combinada de agentes antropogénicos (acumulación de residuos) y naturales» (Farías 2005: 68). En este sentido, estudios recientes confirman que la mayor cantidad de sitios arqueológicos en la zona se ubica en los depósitos aluviales de la planicie de inundación del río Uruguay (albardones y playas) y sobre los cordones litorales arenosos (Bortolotto et al. 2015, Gascue y Bortolotto 2016; Gascue et al. 2016; Loponte et al. 2016a; Bortolotto 2018; Gascue et al. 2019a). En general, los sitios sobre albardón de la margen izquierda del río Uruguay han sido caracterizados como estructuras elípticas de dos metros máximos de altura en zonas de gran vulnerabilidad hidrológica (Gascue et al. 2019a). Sobre la base de la evidencia reunida, los autores consideran que la hipótesis más probable es que correspondan a elevaciones esencialmente naturales (Gascue et al. 2019a).

En el caso particular de la Isla del Vizcaíno, las intervenciones han sido reiteradas desde finales del siglo XIX hasta la actualidad y se han reportado al menos ocho yacimientos elevados diferentes (Figueira 1892; Araújo 1900; Arredondo 1927; Maruca Sosa 1957; Boretto 1968, 1969; Boretto et al. 1973, 1974; Maeso 1977; Gascue et al. 2019a). Los hallazgos de apéndices zoomorfos, campanas, estilos cerámicos incisos, pintados, lisos, con vertederos (entre otros) y los recurrentes hallazgos de inhumaciones humanas directas en tierra, en varios de estos (Maeso 1977; Pi Hugarte 1969; Tuya de Maeso 1980) sugieren que la isla fue ocupada por grupos cazadores-recolectores asimilables a las distintas unidades arqueológicas registradas en la región, desde hace $c .1500$ años (Gascue et al. 2019a). La ocupación guaraní en esta isla fue detectada a través de la identificación de tiestos corrugados y pintados polícromos en varios sitios de la misma (Araújo 1900; Maeso 1977, Maruca Sosa 1957; Gascue et al. 2019a) y de inhumaciones en urna en uno de ellos (Figueira 1892; Araújo 1900; Pi Hugarte 1969).

Las referencias tempranas a estos sitios (Araújo, 1900; Figueira, 1892; Maruca Sosa, 1957) han priorizado los hallazgos de elementos guaraníes, conduciendo a que la isla en su conjunto haya sido reiteradamente vinculada con ocupaciones guaraníes (Bonomo et al. 2015; López Mazz y López Cabral 2020; Noelli 2014; entre otros). No obstante, el registro anteriormente mencionado y nuestras propias observaciones sobre el conjunto cerámico del sitio Isla del Vizcaino 1 (Gascue et al. 2019a) indican que la isla fue mayoritariamente ocupada por grupos cazadores-recolectores locales, constatándose una escasa cantidad de elementos guaraníes que pueden haber arribado a través de distintos procesos en momentos más tardíos.

En cuanto a los procesos de formación de estos sitios y su génesis, no está establecido un consenso; a modo de ejemplo, tanto Figueira (1892) como Arredondo (1927) les adjudican a estas estructuras un carácter constructivo intencional mientras que Maeso (1977), solo a uno (de los ocho yacimientos que identifica) le adjudica génesis antrópica. En los trabajos realizados por Boretto y colaboradores (1973) se afirma que los estratos arqueológicos del sitio Isla del Vizcaíno 1 son generados por desechos y aportes naturales descartando totalmente que se trate de una elevación artificial.

\section{Sitio Isla del Vizcaíno 1}

El sitio Isla del Vizcaíno 1 (Sur 33²1'21,0” - Oeste 58²2’1,3”) se localiza en la isla homónima, en el delta del río Negro, sobre un albardón fluvial a 80 metros del riacho del Vizcaíno (Gascue et 
al. 2019a), compuesto por arenas indiferenciadas de edad holocena (Preciozzi et al. 1985; Fig. 1). En trabajos anteriores (Gascue et al. 2019a), la ocupación del sitio fue asociada a grupos locales de cazadores-recolectores complejos del Holoceno Final, con un patrón de subsistencia basado en recursos del humedal y pastizales adyacentes al río Uruguay, representados por los peces (siluriformes y characiformes varios), el venado de campo (Ozotoceros bezoarticus) y en menor medida los roedores (Cavia aperea e Hydrochoerus hydrochaeris) y aves (Rhea americana). La tecnología cerámica se caracteriza predominantemente por formas abiertas con perfiles simples, de tamaño pequeño y mediano. Desde el punto de vista estilístico, el conjunto cerámico está dominado por tiestos sin decoración (77\%). Entre los decorados se identificaron técnicas de pintura monocroma roja $(15.1 \%)$, y restringido a los bordes incisiones continuas, por surco rítmico y de punto $(5.2 \%)$, labios modelados festoneado y crestados $(1.0 \%)$ y otros que combinan algunas de las anteriores (1.0\%). Finalmente se recuperaron escasos tiestos corrugados en algunos sectores del sitio, localizados en los niveles superiores, señalando así la presencia guaraní en la zona en los últimos momentos de ocupación. La presencia de artefactos líticos en el sitio, se caracteriza por artefactos tallados: lascas, núcleos y escasos instrumentos retocados, mayoritariamente en caliza silicificada y algunos elementos picados/pulidos en arenisca cuarzosa, destacando los llamados litos con hoyuelo (Gascue et al. 2019a). En este mismo sitio, también se recuperó una inhumación primaria durante trabajos de excavación realizados sobre finales de la década de 1960 (Boretto 1969). El conjunto del registro lleva a caracterizar al sitio como un campamento residencial, donde además se realizaron actividades rituales de carácter funerario. Estos aspectos han sido ampliamente registrados a nivel regional, en diversos sitios elevados atribuidos a grupos de cazadores litorales (Figueira 1892; Torres 1911; Maruca Sosa 1957; Bonomo et al. 2010; Gascue et al. 2016; Loponte y Acosta 2016; entre otros).

Los materiales analizados en este trabajo proceden de una excavación de 3 por 2 metros de planta, que alcanzó los 0.85 metros de profundidad (Fig. 2A) resultando estériles los últimos 10 centímetros. A nivel perceptual se distinguieron cuatro unidades estratigráficas (UE) en su totalidad arenosas. La superposición (vista horizontal) de dicha estratigrafía con la nube de puntos generada a partir del registro con estación total de los materiales arqueológicos recuperados en planta (con tamańos $\geq$ a $2 \mathrm{~cm}$; n: 241) muestra que las evidencias materiales se localizan mayoritariamente en las UE II y UE III (Fig. 2B).

De esta secuencia se obtuvieron dos fechados radiocarbónicos (AMS) correspondientes a la base de UE III (nivel 60 a 70 centímetros) y al tope de la misma unidad (nivel 40 a 50 centímetros). El primero, realizado a partir de un fragmento de endocarpo de Syagrus romanzoffiana carbonizado arrojó un resultado de $1510 \pm 30$ años ${ }^{14} \mathrm{C} \mathrm{AP}$ (Gascue et al. 2019a) brindando así una cronología aproximada de los momentos iniciales de ocupación humana del sitio. El segundo, realizado sobre carbón aportó una antigüedad de $1490 \pm 30$ años ${ }^{14} \mathrm{C} \mathrm{AP}\left(\delta^{13} \mathrm{C}-23.9 \%\right.$; Beta545466), no diferenciándose estadísticamente del anterior.

\section{Metodología}

\subsection{Métodos de muestreo}

Se diseñó un plan de muestreo que incluyó a los suelos modificados antrópicamente o potencialmente modificados y a los suelos «naturales», según lo propuesto por Durán (1990) (Fig. 1B). Los primeros fueron identificados a partir de trabajos en campo y por presentar algunas de las siguientes características: mayor elevación, presencia de material arqueológico, sedimentos más oscuros, mayor desarrollo de vegetación. Luego, se abarcaron las zonas con desarrollo de suelos «naturales» (Durán 1990), donde se muestreó planicie, bańados y albardones adyacentes. Todas estas unidades del paisaje no presentaban a priori intervención antrópica prehispánica o al menos 


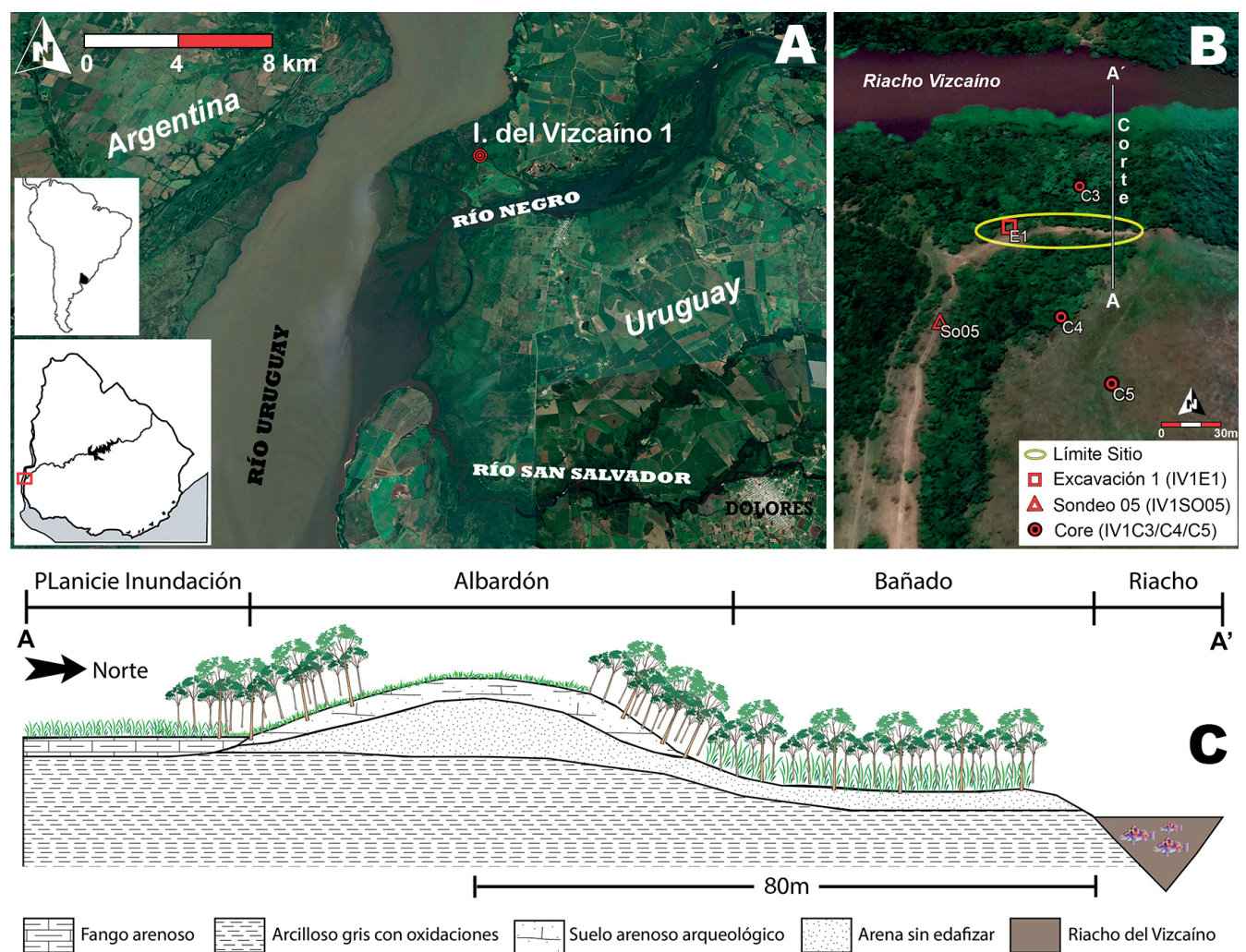

Figura 1. A. Ubicación del sitio; B. Puntos de muestreo; C. Croquis corte estratigráfico modificado de Gascue et al. 2019.

no habían sido reconocidas en ellas las características antes mencionadas. En términos generales se buscó tener registro de la mayor cantidad de unidades ambientales para poder comparar e identificar posibles zonas de aportes sedimentarios.

Para el análisis de suelos modificados antrópicamente se trabajó con 14 muestras obtenidas en intervalos continuos de cinco centímetros de potencia de base a tope del perfil oeste de la excavación IV1E1PW comprendiendo desde 0.75 hasta 0.05 metros de profundidad (Fig. 2B). Al momento de la toma de muestras se realizó también el relevamiento estratigráfico del perfil de excavación y la caracterización de los depósitos a nivel perceptivo por: color (utilizando tabla Munsell), textura al tacto, estructuras, bioturbación, rasgos pedológicos, así como de todas aquellas características macroscópicas que aportan a la discriminación de posibles unidades estratigráficas (Harris 1977; Gasche y Tunca 1983; Stein 1990). De esta forma se reconocieron cuatro unidades estratigráficas: tres unidades arqueológicas (UEI, UEII y UEIII) y una cuarta arqueológicamente estéril (UEIV) (Fig. 2B). A pesar de que en el sector del perfil oeste de donde se tomaron las muestras solo se alcanzó a intervenir el tope (transicional) de la UEIV, en otros sectores de la excavación se alcanzó mayor profundidad $(90 \mathrm{~cm})$ y se constató el desarrollo de una unidad de arenas cada vez más claras con ausencia de material arqueológico (Fig. 2B).

El muestreo de suelos naturales se realizó de dos formas; por un lado, se practicó un sondeo de 0.50 por 0.50 metros de 0.75 metros de profundidad en la zona del albardón sin aparente alteración antrópica ni presencia de material arqueológico (IV1SO05; Fig. 1B) y se tomaron muestras continuas de la base al tope. Por otro lado, las muestras del Bańado (IV1C3), Monte (IV1C4) y Planicie (IV1C5; Fig. 1B) se tomaron usando muestreador AMS Corer Soil Sampler que permite obtener muestras encapsuladas sin perturbar en secuencias continuas. Cada cápsula, de 15 centí- 


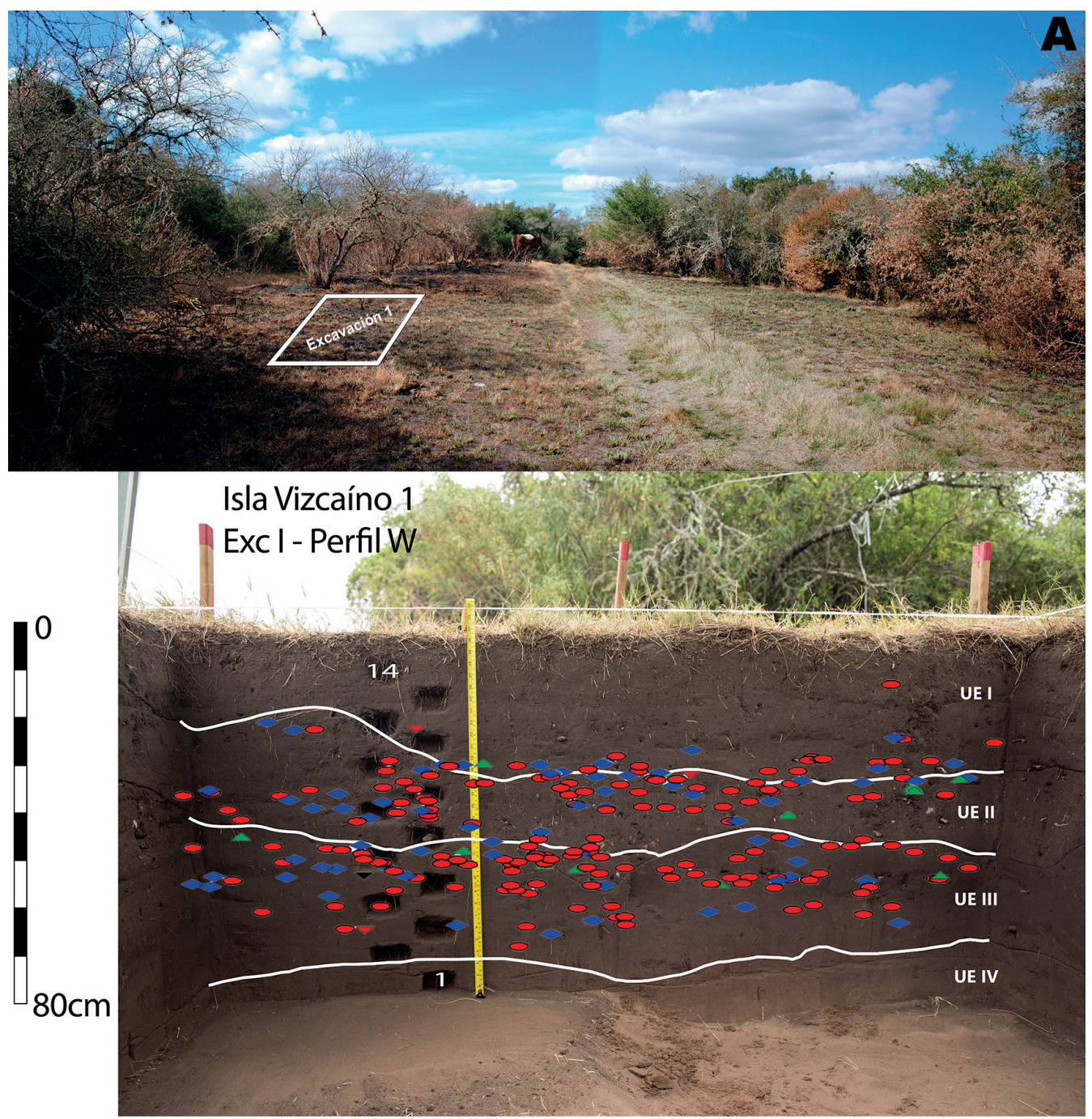

UEI - Arena fina a media con limo 10YR 3/1 (Arqueológica)

UEII - Arena fina a media con limo (contiene óseo calcinado, carbón y TQ) 10YR 3/1 (Arqueológica) UEIII - Arena media y fina se aclara hacia base 10YR 2/1 (Arqueológica)

UEIV - Arena media a fina se aclara hacia abajo 10YR 4/2 (Esteril)

$\checkmark$ Cerámica $\sim$ Lítico $\triangle$ Tierra quemada

Figura 2. A. Vista del sitio Isla del Vizcaino 1 con localización de Excavación 1; B. Relevamiento perceptual en campo de perfil Oeste de la Excavación 1 con superposición de nube de puntos de material arqueológico registrado tridimensionalmente con estación total.

metros de largo y cinco centímetros de diámetro, fue dividida en tres submuestras de cinco centímetros cada una y se seleccionaron para los análisis intervalos cada 10 centímetros.

\subsection{Métodos analíticos}

Los antrosoles pueden ser definidos como suelos que han sido física y químicamente modificados por las actividades humanas (Certini y Scalenghe 2011; Capra et al. 2015; Dazzi y Lo Papa 
2015; Howard 2017). Por esto, los análisis de las propiedades texturales (físicas) y geoquímicas de los mismos han ganado importancia como técnica relevante en las investigaciones arqueológicas (Sombroek 1966; Sombroek et al. 2002; Arroyo-Kalin et al. 2009; Schmidt y Heckenberger 2009). En este contexto, para el este trabajo se seleccionó un conjunto de análisis sedimentológicos, que incluyó la caracterización texturo-composicional y geoquímica, para ser aplicado en cada secuencia sedimentaria partiendo de un abordaje mensurativo comparativo.

El análisis granulométrico se realizó siguiendo metodología estándar. Para el pretratamiento de las muestras sedimentarias se procedió de la siguiente manera: cuarteo y secado en horno a $70{ }^{\circ} \mathrm{C}$ durante 48 horas; análisis de colorimetría en seco utilizando tabla Munsell; pesado de entre 20 y 50 gramos de muestra seca; eliminación de materia orgánica con $\mathrm{H}_{2} \mathrm{O}_{2} 30$ volúmenes en baño de agua a $70{ }^{\circ} \mathrm{C}$; eliminación de carbonatos (en caso necesario) con $\mathrm{HCl} 10 \%$; dispersión de arcillas en baño de ultrasonido con hexametafosfato de sodio al $4 \%$. El contenido de gravas y arenas se determinó mediante tamizado, usando una secuencia de mallas a $1^{\circ}$ phi (phi -2 a phi 4; Wentworth 1922). Las fracciones de limo y arcilla se determinaron mediante el Método Internacional de la Pipeta (Carver 1971), tomando alícuotas a intervalos de $1^{\circ}$ phi (phi -5 a phi 9).

Para el análisis composicional se siguió la propuesta de Howard y colaboradores (Howard et al. 2015; Howard y Orlicki 2015, 2016), registrando el contenido de macroartefactos (>2 mm) y microartefactos $(0.25$ a $2 \mathrm{~mm})$ en las fracciones de grava y de arena respectivamente. En este sentido, se observaron las fracciones de grava $(4000$ y $2000 \mu \mathrm{m})$ y arena media y gruesa $(1000,500$ y $250 \mu \mathrm{m}$ ) bajo lupa binocular para identificar y cuantificar elementos naturales (v.g. minerales) y material arqueológico (carbones, nódulos de tierra quemada, material óseo, entre otros). En el caso de las gravas se observó la totalidad de las fracciones retenidas y para las arenas 0,05 gramos o su totalidad en caso de que la cantidad de sedimento no llegara al peso estipulado. También fue analizado el grado de redondeamiento y las distintas formas representadas en las fracciones observadas (Pettijohn et al. 1973). Fue elaborada una ficha de análisis para la observación a lupa y se realizó un registro con cámara fotográfica. Estos análisis se realizaron en el Laboratorio de Arqueología y Geociencias del Centro Universitario Regional del Este (CURE-UdelaR). Asimismo, los análisis composicionales de la fracción lítica de las muestras fueron realizados por difracción de rayos $\mathrm{X}$ (XRD) de polvos de muestra total, en configuración Bragg-Brentano mediante un difractómetro Empyrean de Panalytical, con ánodo de cobre. Estos análisis fueron efectuados en el Laboratorio del Departamento de Desarrollo Tecnológico (CURE-UdelaR). A partir de los resultados granulométricos y composicionales, se calcularon los estadísticos sedimentológicos propuestos por Folk y Ward (1957) y, Folk y colaboradores (1970) y se procedió a la identificación textural de las secuencias sedimentarias, utilizando para ello los diagramas propuestos por Howard (2017).

En cuanto a los análisis geoquímicos, se realizó la determinación del contenido de materia orgánica por el método de pérdida de peso por ignición (Heiri et al. 2001). Conjuntamente, se remitieron muestras al Laboratorio de Suelos y Aguas del Instituto Nacional de Investigaciones Agropecuarias (INIA), para el análisis de acidez ( $\mathrm{pH}$ en agua) y de fósforo disponible o (Bray I).

\subsection{Integración y análisis estadístico}

Los datos generados mediante las distintas variables analizadas fueron integrados en una matriz y se procedió a su estandarización (a cada valor se le restó la media y se dividió por el desvío estándar). Se efectuó un análisis de componentes principales, con el objetivo de estudiar la ordenación de las muestras según su procedencia y su relación con componentes resultantes. Estos análisis se efectuaron con el programa PAST 3.0 (Hammer et al. 2001). Para la comparación de los difractogramas obtenidos mediante XRD de polvo se utilizó el coeficiente de correlación $r$ de Pearson, utilizando para su cálculo el programa R (R Core Team 2017). 
A partir del análisis integrado de los datos se discute si los suelos antropogénicos identificados en Isla del Vizcaino 1 corresponden a antrosoles metagenéticos (HAM: Human-altered material) o neogenéticos (HTM: Human-transported material) según lo indicado por Soil Survey Staff (2014). Los antrosoles metagenéticos se producen por procesos de enriquecimiento a partir de aportes de actividades in situ, es decir que no responden a un gesto técnico de transporte y acondicionamiento de material constructivo. La preparación, traslado y acumulación de sedimentos, genera suelos de tipo neogenéticos (Howard 2017). Identificar qué tipo de antrosol está presente en el sitio Isla del Vizcaíno 1 implica, por ende, caracterizar sus procesos de formación y brindar evidencias que permitan sustentar alguna de las hipótesis que se vienen discutiendo hace más de un siglo.

\section{Resultados}

En la figura 3 se representa gráficamente la secuencia sedimentaria registrada en IV1E1, con la distribución vertical de los resultados obtenidos para los distintos indicadores analizados (granulometría, composición y geoquímica). La zonación resultante del análisis de cluster con ajuste estratigráfico, muestra una buena correspondencia con la estratigrafía arqueológica definida en campo. La excepción está dada por la muestra inferior (M1) que en campo fue atribuida al tope de la UEIV caracterizada en otros sectores de la excavación. El conjunto de indicadores analizados en este trabajo incluye a esta muestra en la unidad suprayacente, identificando tres unidades arqueológicas. La unidad basal, de color marrón grisáceo oscuro (10YR4/2), se extiende entre los 75 a 50 centímetros y se ubica cronológicamente hacia los 1500 años AP, se caracteriza por una media granulométrica de arena fina, con muy bajo contenido de gravas y pelitas. A nivel composicional lo observado a lupa (y su posterior análisis por difracción de rayos $\mathrm{X}$ ) muestra que predomina la fracción mineral (cuarzo y feldespato), con presencia de tierra quemada como elemento cultural. Los indicadores geoquímicos indican altos valores de fósforo disponible (400-500 ppm), bajos contenidos de materia orgánica ( $\operatorname{circa} 2$ a $3 \%$ ) y pH levemente ácido (6.5). La segunda unidad, desarrollada entre los 50 y los 15 centímetros de profundidad, presenta una coloración más oscura (10YR3/2) en una matriz igualmente arenosa, pero con mayor contenido de pelitas y una textura media de arena muy fina. Es la unidad que presenta mayor contenido de micro y macroartefactos (incluyendo tierra quemada, restos faunísticos y carbón vegetal), así como los valores máximos de fósforo disponible (600 ppm) y materia orgánica (3\%). La última unidad, que comprende entre los 15 y el tope de la secuencia, presenta una coloración gris muy oscura (10YR3/1) y una textura media de arena fina. El contenido de material cultural disminuye respecto a la unidad anterior, al igual que los valores de fósforo, materia orgánica y $\mathrm{pH}$. El análisis de los grados de redondeamiento de los macroartefactos y microartefactos (Wentworth 1922) mostró predominancia de baja esfericidad (subredondeadas, subangulares y angulares) con formas planas e irregulares principalmente. Todo el material presente en la matriz que no era microartefacto o macroartefacto, es decir, minerales, concreciones, etc. presentó baja esfericidad (mayormente subredondeados) y formas predominantemente equidimensionales.

De acuerdo con la caracterización de antrosedimentos propuesta por Howard (2017), los datos de granulometría y composición permiten identificar la existencia de un antroarenosol en IV1E1 con dos unidades con características particulares. Entre los 75 y 50 centímetros (correspondiente con la UEIII) se desarrolla un antroarenosol cuarzo feldespático. A partir de los 50 centímetros y hasta el tope de la secuencia (UEII y UEI) el suelo presenta características de un antroarenosol fangoso cuarzo feldespático. La diferencia entre ambos es el mayor predominio de fangos en la segunda (Howard 2017; Fig. 4).

La secuencia sedimentaria del albardón sin material arqueológico (IV1SO05) es representada en la figura 5. En esta se observa que predominan las arenas medias de mala selección con coloraciones que van desde el gris marrón claro $(10 \mathrm{YR} 6 / 2)$ en los primeros 60 centímetros al gris claro 


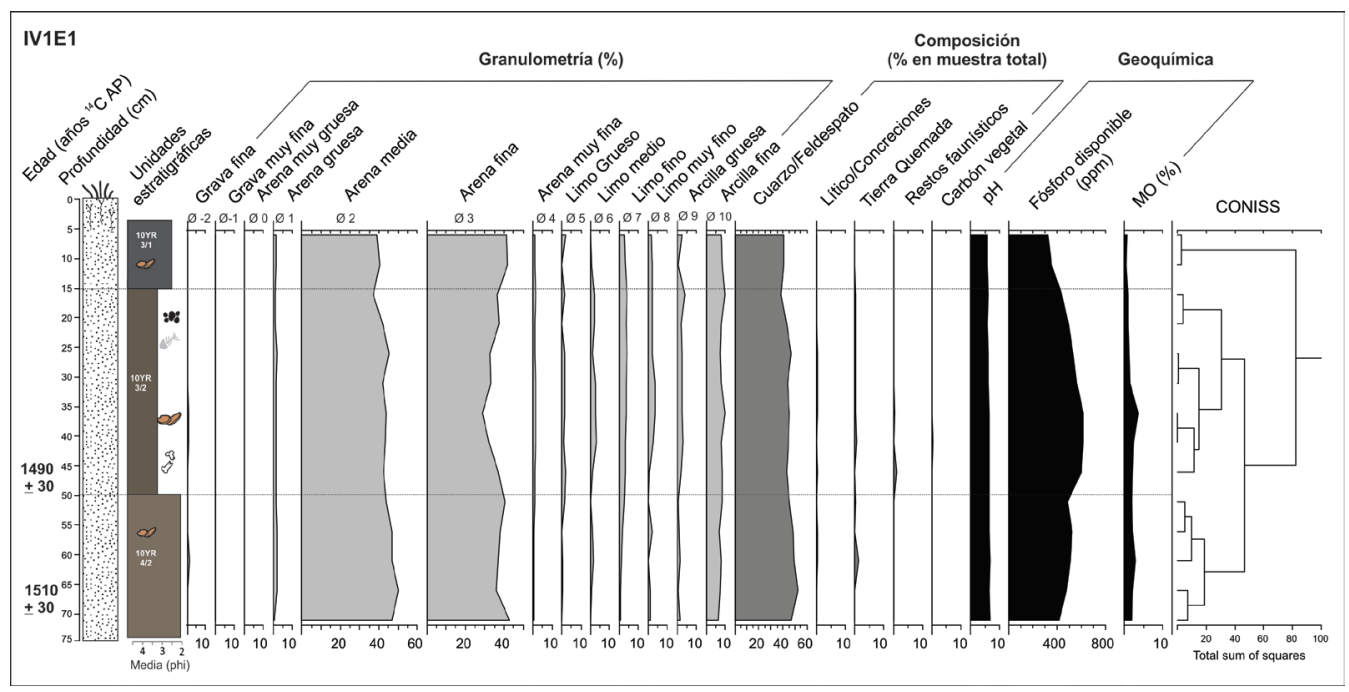

Figura 3. Perfil estratigráfico de IVIE1 con las dataciones radiocarbónicas y la distribución vertical de abundancia relativa de las fracciones granulométricas, componentes culturales y minerales e indicadores geoquímicos analizados, junto a la zonificación resultante del análisis de cluster con ajuste estratigráfico.

(10YR7/2) en los últimos 20 centímetros. Los valores de $\mathrm{pH}$ y materia orgánica muestran una correspondencia con los suelos de textura arenosa de Uruguay (Céspedes 2007) alcanzando valores promedio de 5.8 y 0.9 respectivamente. El fósforo disponible alcanza las $20 \mathrm{ppm}$ en el tope del perfil disminuyendo levemente hasta alcanzar las 13 ppm en la base. En cuanto a la composición, se constató la presencia de cuarzos y feldespatos en más del 99\% de las fracciones observadas a lupa con formas subredondeadas que oscilaron entre irregulares y equidimensionales.

Las tres unidades del paisaje restantes (bañado, planicie y monte) están caracterizadas por el predomino de texturas limosas. En la figura 6, se observa la secuencia estratigráfica obtenida en el bañado (IV1C3) a través de muestras encapsuladas, la cual denota la presencia de tres unidades sedimentarias con coloración marrón grisáceo (10YR5/2). De la parte basal del testigo hasta los 16 centímetros se observa una predominancia de las arenas muy finas a finas, con valores de $\mathrm{pH}$ ácidos (6.2) y concentraciones de materia orgánica que promedian $2.18 \%$. En el centro del testigo (entre los 8 y 16 centímetros) a nivel granulométrico se evidencia una disminución de la arena media pero también un aumento de la arcilla fina; el $\mathrm{pH}$ se mantiene constante, pero hay un incremento de la materia orgánica que alcanza valores promedio de $8.07 \%$. Finalmente, los ocho centímetros superiores, presentan una matriz arcillosa con una notoria disminución de las arenas; el $\mathrm{pH}$ se mantiene ácido pero la materia orgánica aumenta sustancialmente alcanzando el valor de $18.62 \%$. Toda la secuencia presenta valores de fósforo disponible de 357 ppm en promedio. En cuanto al análisis de composición realizado, los sedimentos del bañado contienen concreciones en las fracciones más finas, pero sin que estas superaran el 5\%, siendo la matriz de esta muestra cuarzos y feldespatos con formas subredondeadas a subangulosas, irregulares y equidimensionales. Los datos composicionales fueron corroborados mediante difracción de rayos $\mathrm{X}$.

Las muestras correspondientes a IV1C4 son representadas en la figura 7 donde se observa la presencia de tres grandes unidades. En la parte inferior que se ubica entre 16 y 21 centímetros, se denota una coloración gris marrón claro $(10 \mathrm{YR} 6 / 2)$ con mayor contenido de arcilla fina y limo muy fino; el pH es ácido (5), la materia orgánica se encuentra en $9.27 \%$ y el fósforo disponible es de 2 ppm. Hacia el centro del testigo (entre los 10 y 16 centímetros) la coloración es gris (10YR6/1), disminuyen las arcillas finas y aumentan los limos finos y muy finos; el pH se mantiene constante 

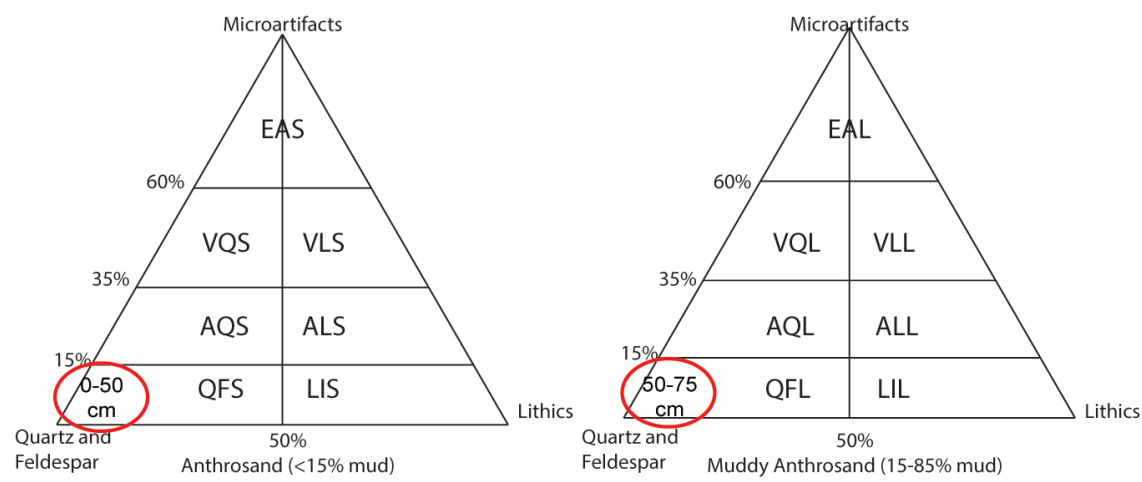

Figura 4. Clasificación composicional de sedimentos antropogénicos (cf. Howard 2017) de IV1E1.

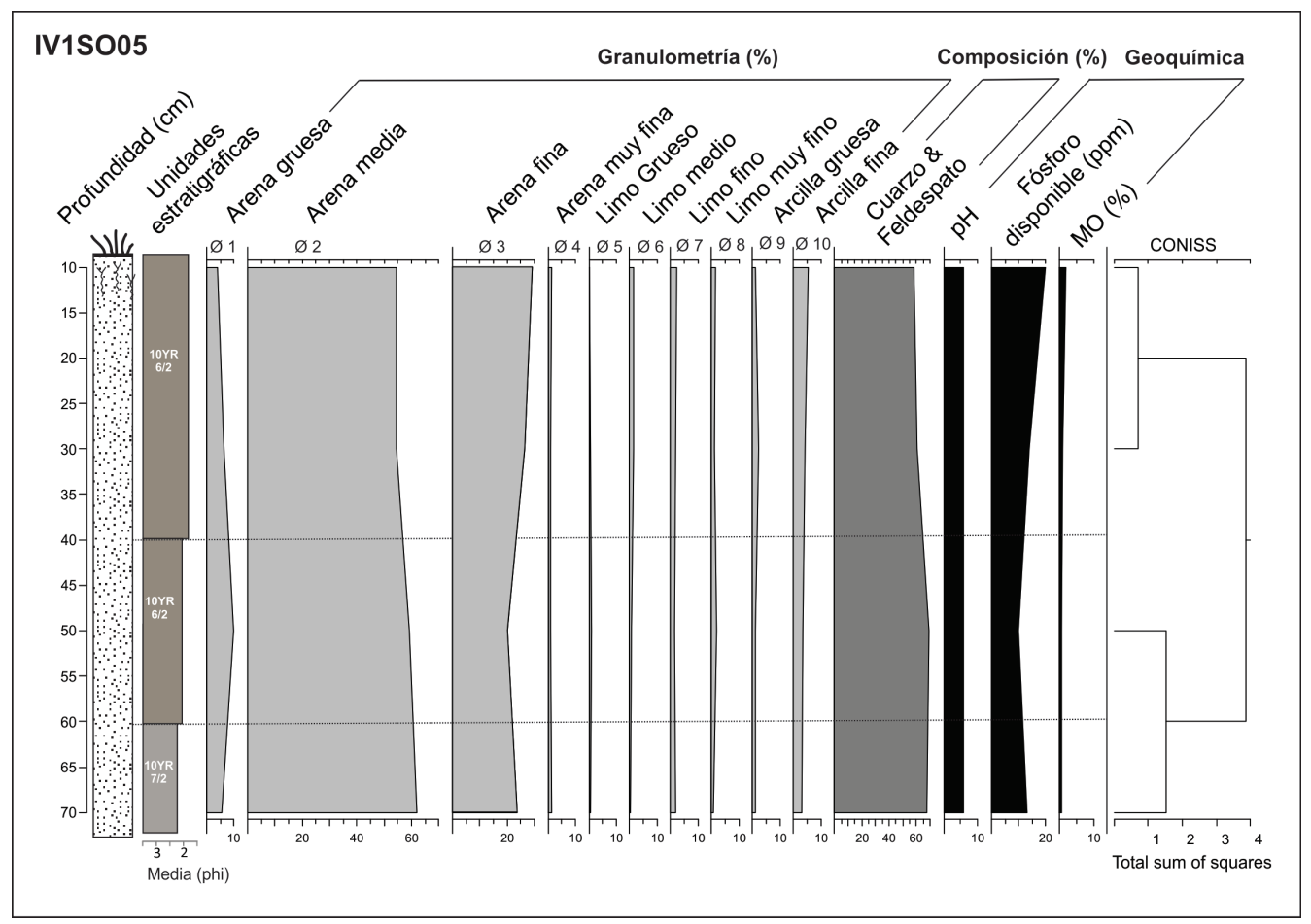

Figura 5. Perfil estratigráfico de IV1SO05 con distribución vertical de abundancia relativa de las fracciones granulométricas, componentes minerales e indicadores geoquimicos analizados, junto a la zonificación resultante del análisis de cluster.

al igual que la materia orgánica mientras el fósforo disponible tiende a aumentar. En el nivel superior que abarca los 10 primeros centímetros del testigo, se observa también una coloración gris (10YR6/1) con mayor presencia de arenas finas y medias, el $\mathrm{pH}$ sigue siendo ácido, aumentando la materia orgánica $(7.51 \%)$ y el fósforo disponible $(20 \mathrm{ppm})$. El análisis composicional (corroborado mediante difracción de rayos $\mathrm{X}$ de polvo) realizado en las fracciones más gruesas de estas muestras señala que la matriz está compuesta por cuarzos y feldespatos con formas subredondeadas a subangulosas, irregulares y equidimensionales. 


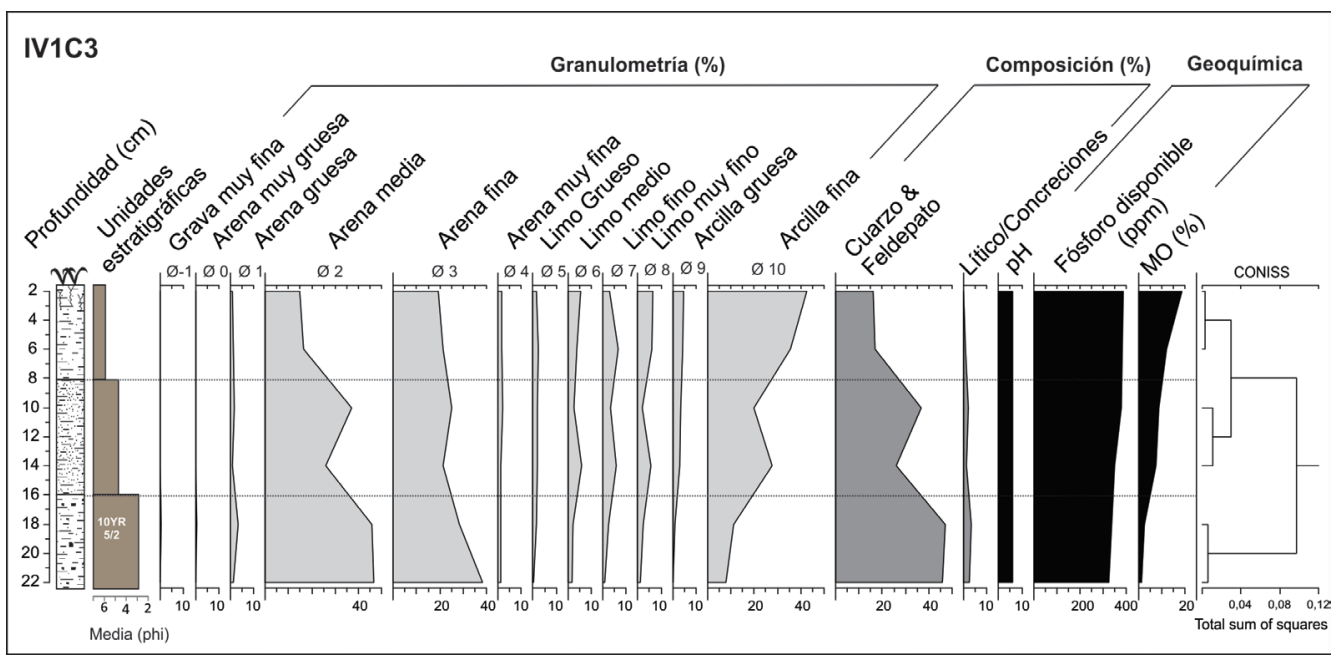

Figura 6. Perfil estratigráfico de IV1C3 con distribución vertical de abundancia relativa de las fracciones granulométricas, componentes minerales e indicadores geoquimicos analizados, junto a la zonificación resultante del análisis de cluster.

Por último, se representan en la figura 8 las muestras correspondientes a la planicie (IV1C5) que se agrupan en dos unidades de igual coloración marrón grisáceo (10YR5/2). La parte inferior del perfil (4 a 20 centímetros) presenta concentraciones más altas de arenas finas y medias; el pH es ácido, el porcentaje de materia orgánica en promedio es de $4.9 \%$ y el fósforo disponible es de 7 ppm. En el extremo superior que se extiende en los cuatro centímetros iniciales del testigo, predominan las arcillas, el contenido de materia orgánica es superior a $8 \%$, el pH continúa siendo ácido (5.6) y la cantidad de fósforo disponible es sensiblemente menor (4 ppm). Al igual que en IV1C4, el análisis composicional realizado en las fracciones más gruesas (bajo observación a lupa y posteriormente corroborado por difracción de rayos $\mathrm{X}$ de polvo) señala que la matriz está compuesta por cuarzos y feldespatos con formas subredondeadas a subangulosas, irregulares y equidimensionales.

En la figura 9 se presenta gráficamente el resultado del análisis de componentes principales (ACP). El primer componente, que explica el $48 \%$ de la varianza, se halla definido principalmente por las variables granulométricas. Con valores positivos (conjuntos D, E, F) se ubican las muestras de texturas más gruesas (mayores contenidos de gravas y arenas), mientras que en el sector izquierdo se agrupan las muestras de textura más fina (conjuntos $\mathrm{A}, \mathrm{B}$ y C). El segundo componente, que explica el $12 \%$ de la varianza, ordena las muestras por sus propiedades composicionales y geoquímicas, ubicando en la mitad superior a aquellas con contenido de micro y macroartefactos, y mayores valores de $\mathrm{pH}$, fósforo disponible y materia orgánica. La distribución de las muestras, de acuerdo a estos dos componentes, permite distinguir agrupamientos que se corresponden con la procedencia de las distintas unidades de muestreo. El primer componente separa las secuencias del monte, la planicie y el sector superior del bañado de las secuencias arenosas procedentes del albardón. El segundo componente permite diferenciar, dentro de la unidad del albardón, la secuencia del antrosol de aquella procedente del sector sin modificación antrópica. El único conjunto que presenta muestras de distintas procedencias es el E, que reúne la base de la excavación IV1E1 con el sector inferior del núcleo tomado en el bañado IV1C3. Estas muestras comparten similares características granulométricas (media de arena fina y muy fina) y geoquímicas. A modo de ejemplo, se presentan en la figura 10 los difractogramas de las muestras IV1E1M1, IV1E1M2 y IV1E1M3 (correspondientes a la parte basal de la excavación) y de la muestra IV1C3T3 (base del bañado). A partir de un análisis de correlación de Pearson, el coeficiente de correlación $r$ es de 0.8057 para IV1E1M1 - IV1C3T3, de 0.9499 para IV1E1M2 


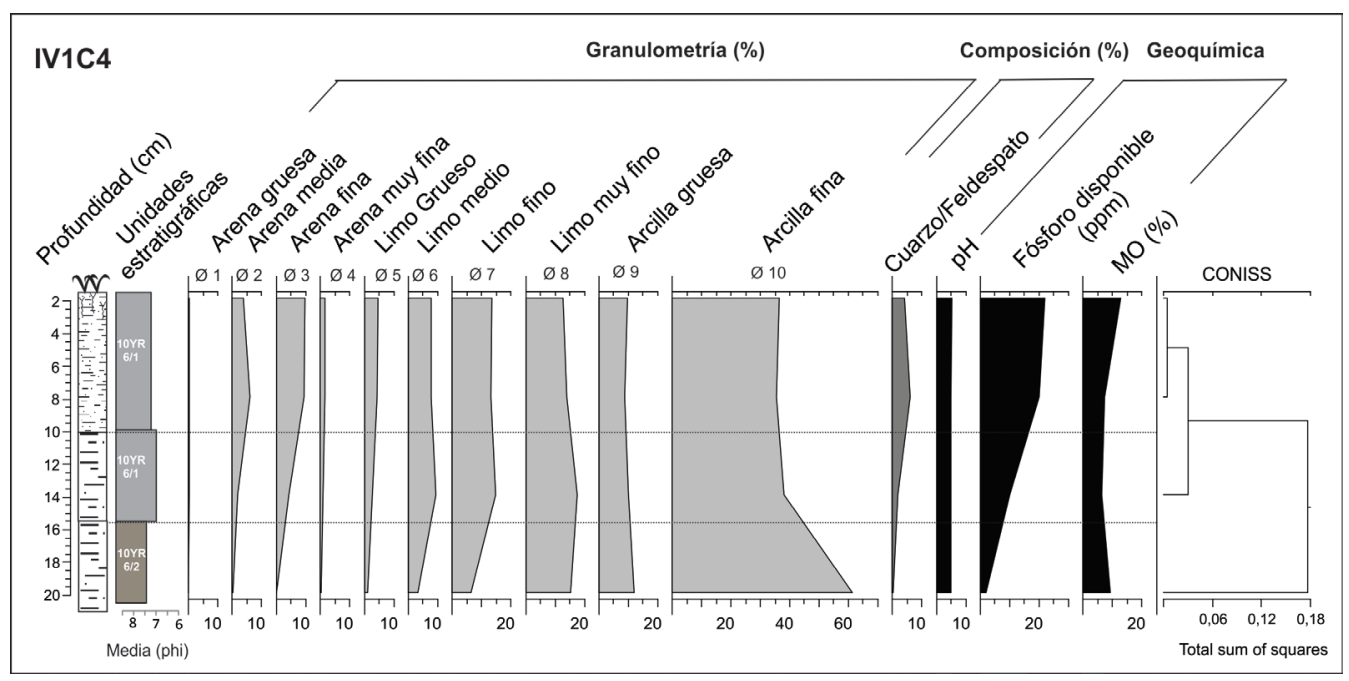

Figura 7. Perfil estratigráfico de IV1C4 con distribución vertical de abundancia relativa de las fracciones granulométricas, componentes minerales e indicadores geoquímicos analizados, junto a la zonificación resultante del análisis de cluster.

- IV1C3T3 y finalmente de 0.9134 para IV1E1M3 - IV1C3T3. Estos valores indican una fuerte correlación especialmente para el caso IV1E1M2 - IV1C3T3.

\section{Discusión y conclusiones}

Desde comienzos del siglo XIX en el desarrollo de la arqueología de la margen izquierda del bajo río Uruguay, los sitios elevados han sido catalogados como túmulos, por la mayoría de los investigadores. De esta forma se les ha adjudicado un carácter antropogénico constructivo y por ende intencional, lo cual ha sido rechazado por muy pocos autores (Boretto et al. 1973; Gascue et al. 2016, 2019a).

Los resultados alcanzados en este trabajo muestran dos grandes grupos granulométricos principales. Por un lado, están las muestras procedentes del albardón (IV1E1 y IV1SO05), caracterizadas por el predominio de las fracciones de arena (Figs. 3 y 5). Por otro lado, las secuencias obtenidas de las otras unidades del paisaje (bañado, planicie y monte) que se caracterizan por el predominio de limos (Figs. 6 a 8). A partir del uso de la clasificación propuesta por Folk (1969) se constató que los sedimentos provenientes de IV1E1 son de textura areno fangosa y areno fangosa levemente gravosa, situación similar a la observada en las muestras de IV1SO05. Los análisis de granulometría, composición y geoquímica realizados identificaron en IV1E1 tres unidades estratigráficas comprendidas en su mayoría por arenas medias y finas. Estas tres unidades contienen materiales culturales (cerámica, lítico, restos de fauna, tierra quemada y carbón cultural), coloraciones oscuras y altos valores de materia orgánica y fósforo disponible. Estas firmas químicas (que indican la modificación antrópica del suelo) son dejadas por las distintas actividades llevadas adelante por los grupos humanos en los sitios que ocupan ( $v$.g. alimentación, gestión de residuos, vivienda y tratamiento de sus muertos, entre otras; Kern y Kämpf 1989; Lima et al. 2002; Sombroek et al. 2002). El uso de la clasificación propuesta por Howard (2017) para este sitio identificó un antroarenosol con características de antroarenosol fangoso cuarzo feldespático en la parte superior y de antroarenosol cuarzo feldespático en el sector inferior.

El conjunto de características observadas en los sedimentos de la excavación está ausente en los suelos circundantes, incluso en aquellos como IV1SO05, que presenta similar matriz sedimen- 


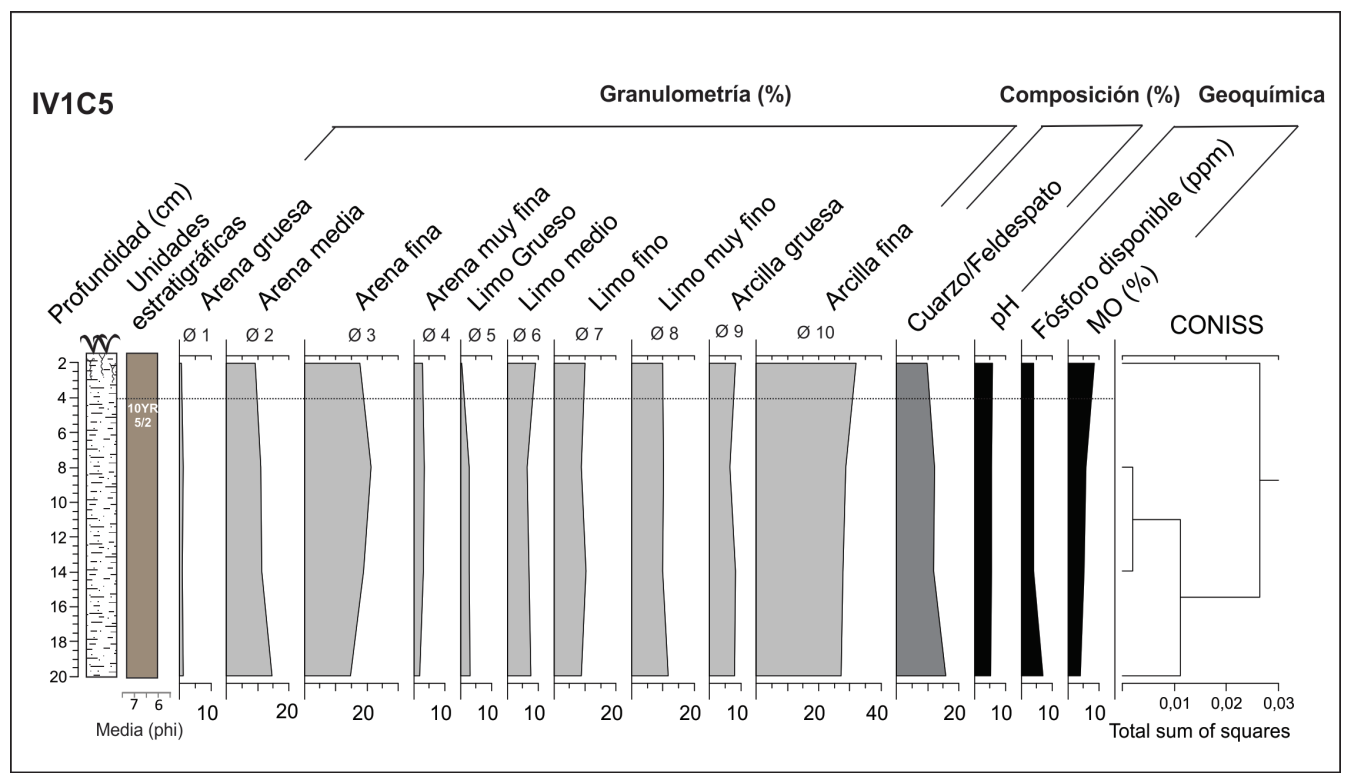

Figura 8. Perfil estratigráfico de IV1C5 con distribución vertical de abundancia relativa de las fracciones granulométricas, componentes minerales e indicadores geoquímicos analizados, junto a la zonificación resultante del análisis de cluster.

taria. Los resultados de las muestras provenientes del bañado, monte y planicie indican la presencia mayoritaria de texturas fangosas. El uso de estas últimas, sumado al aporte de materiales culturales gruesos ha sido vinculado con estrategias tendientes a dar cohesión y consolidación estructural en los cerritos del este del Uruguay (Bracco et al. 2000; Castiñeira et al. 2013, 2014, Castiñeira y Piñeiro 2000; López Mazz 1992; Politis et al. 2011). En el caso del río Paraná, estudios realizados por Castińeira y colaboradores (2013) indicarían que las zonas de préstamo (con texturas finas) para las estructuras monticulares de Los Tres Cerros 1 estarían en las márgenes fluviales de los arroyos tributarios del mencionado río (Castiñeira et al. 2014). Sin embargo, en el caso de estudio de este trabajo, si bien estas texturas están disponibles en los suelos adyacentes, las mismas no están presentes en el albardón.

Tal como se muestra en el ACP de la figura 9, el conjunto E agrupa muestras que se corresponden con las zonas basales de IV1C3 y de IV1E1, debido a la similitud en características geoquímicas y granulométricas (arenas). En el caso de las primeras, la presencia de altas concentraciones de fósforo disponible en el tope de la secuencia del bañado puede estar relacionada con el aporte de fertilizantes fosforados de los actuales cultivos en la cuenca que llegan a los cursos de agua por escorrentía ( $c f$. Chalar et al. 2014). La similitud granulométrica entre ambos sectores de las secuencias podría indicar el desarrollo de un antrosol neogenético en el sitio arqueológico, a partir del traslado de sedimentos arenosos desde el bañado hacia dicho sitio. Sin embargo, resultaría una inversión de trabajo innecesario ya que las mismas texturas están presentes en todo el resto del albardón y no colaborarían en la consolidación de una futura estructura elevada artificialmente. Por el contrario, estas similitudes son concordantes con un proceso natural por el cual los sedimentos de desborde se depositan simultáneamente en ambas unidades (bańado y albardón) durante los eventos de creciente. Por esto último, y a raíz de todos los datos obtenidos, podemos definir al sitio Isla del Vizcaíno 1 como un antroarenosol metagenético, es decir, un arenosol antrópico formado in situ a partir de sedimentos preexistentes modificados en mayor o menor medida por acción humana. Las evidencias generadas no sustentan la existencia de un antrosol neogenético que implicaría material parental transportado intencionalmente con fines acrecionales (Soil Survey Staff 2014). 


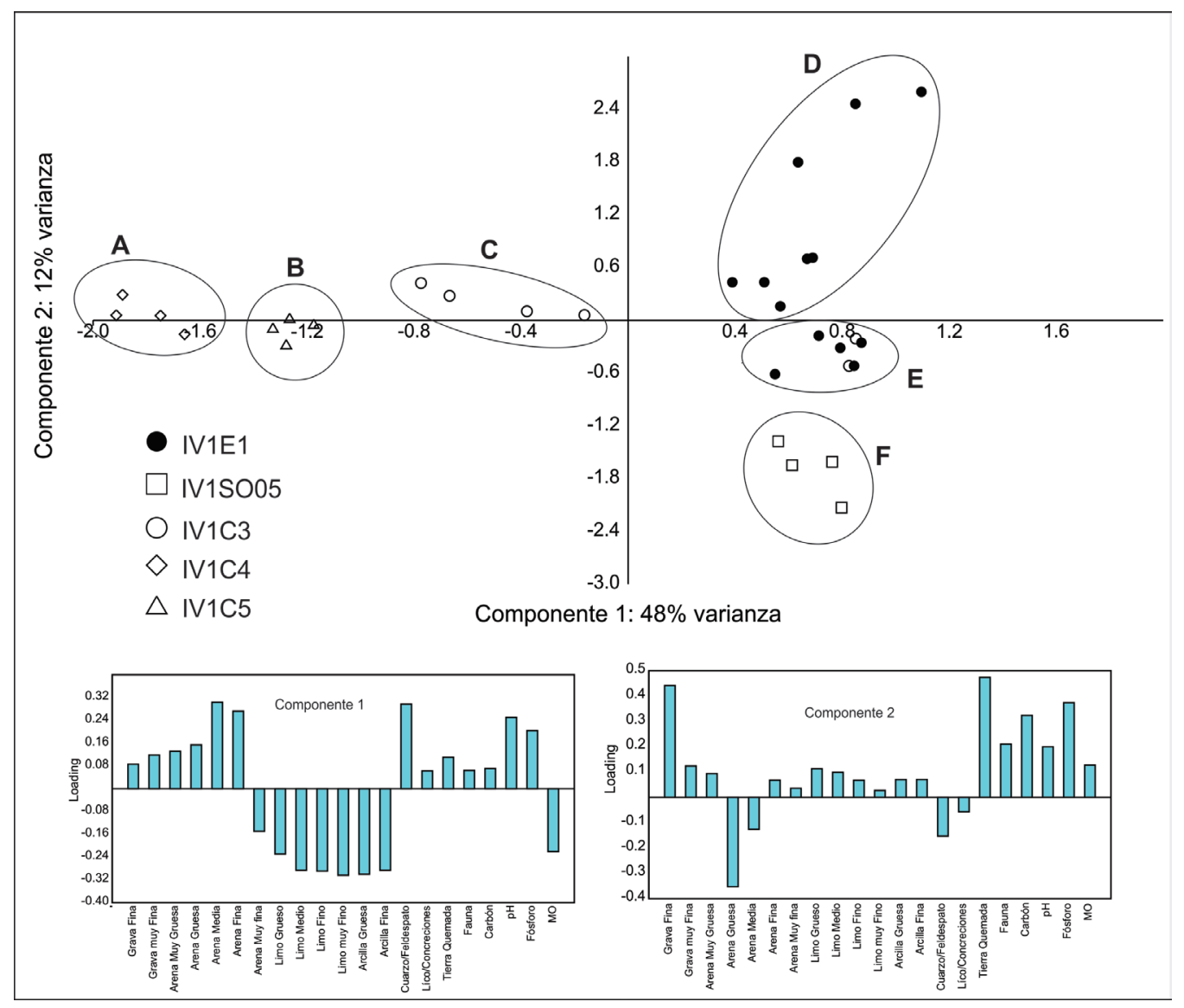

Figura 9. Análisis de componentes principales de IV1E1; IV1SO05; IV1C3; IV1C4; IV1C5.

Los sitios de Isla del Vizcaino han sido postulados de una manera acrítica por diferentes autores como estructuras construidas. El enfoque abordado en este trabajo busca incorporar nuevas líneas de evidencias que promuevan una discusión íntegra y rigurosa de los procesos de formación de sitios. El conjunto de evidencias generado durante la propia excavación arqueológica y los análisis posteriores, incluyendo los datos aquí presentados, permite identificar un suelo modificado antrópicamente, producto de una ocupación humana intensa sobre un albardón al que se le incorporaron materiales culturales y nutrientes en altas concentraciones, pero sin evidencias de aportes antropógenicos de sedimentos destinados a elevar de manera artificial al mencionado albardón.

El antrosol identificado puede ser descrito como un suelo bien drenado, de textura fangoarenosa a arenosa, de coloración más oscura respecto a los suelos adyacentes y con valores considerablemente mayores de $\mathrm{pH}$, materia orgánica y fósforo disponible. Estas características químicas son generalmente consideradas como evidencia de antropogénesis (Kern et al. 2017). Los restos materiales (macro y microartefactos) recuperados durante la excavación, la zaranda de agua y mediante el propio análisis composicional, indican que este antrosol pudo haberse generado mediante la acumulación de desechos orgánicos perecederos junto a residuos más durables como fragmentos cerámicos, líticos, faunísticos y macrobotánicos. La frecuente evidencia de termoalteración en muchos de estos materiales (huesos quemados, endocarpos carbonizados, nódulos de tierra quemada, entre otros), sugieren que el fuego cumplió un rol central en la gestión de estos materiales, previo a su depósito final. Procesos similares de gestión de residuos y generación de 

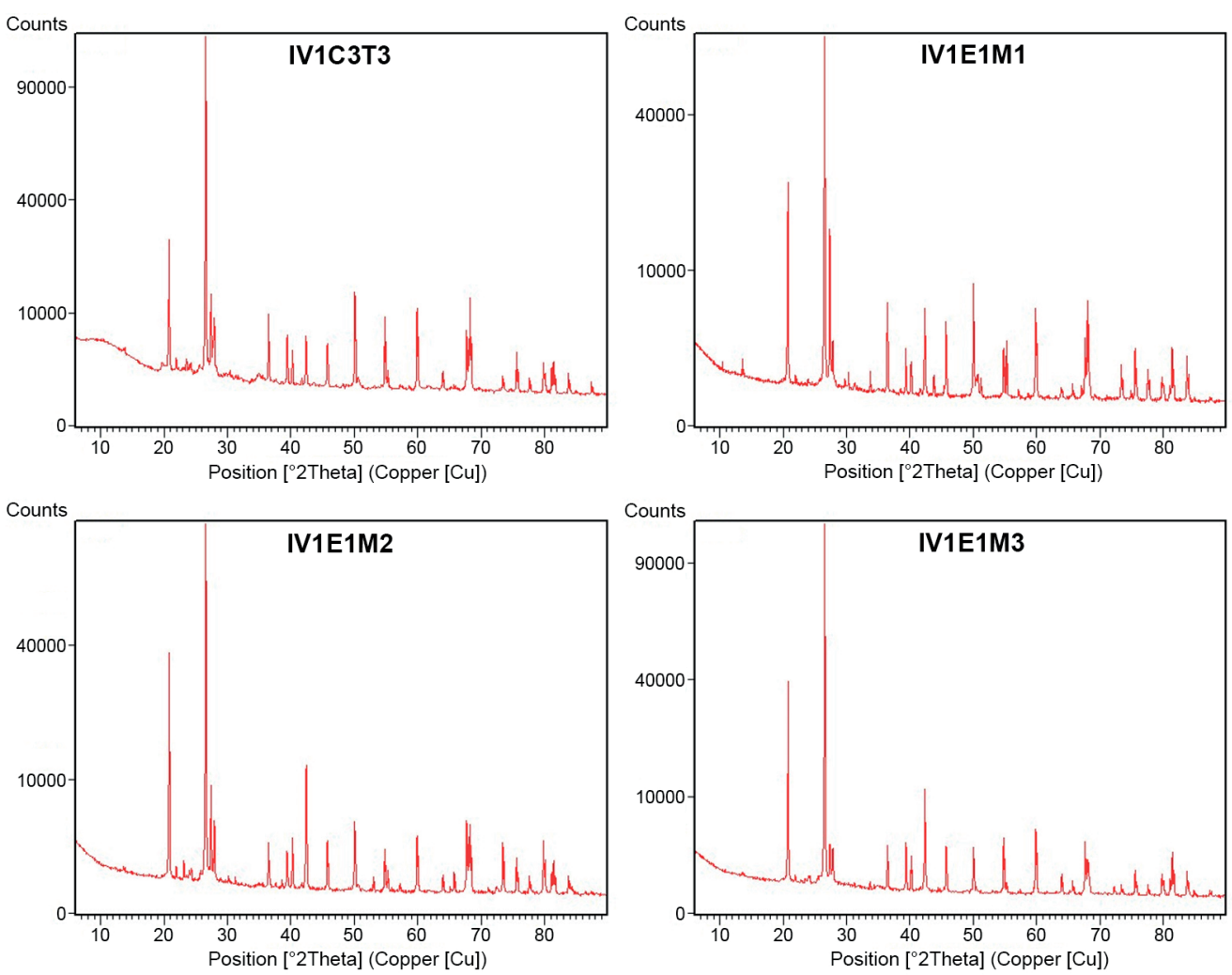

Figura 10. Difractogramas de raxos X de polvo en muestras totales, de IV1C3T3; IVIE1M1; IV1E1M2; IV1E1M3.

suelos antrópicos, han sido ampliamente estudiados y descritos en distintas partes de Sudamérica, con énfasis en las tierras bajas amazónicas (Sombroek 1966; Kern y Kämpf 1989; Schmidt y Heckenberger 2009; Arroyo-Kalin et al. 2009; Capra et al. 2015; Kern et al. 2017; Sombroek et al. 2020; entre otros).

La ocupación del sitio se habría iniciado hace circa 1500 años. Los materiales fechados para los niveles de 60 a 70 centímetros y de 40 a 50 centímetros no son diferenciables estadísticamente. Hasta la fecha no se dispone de información que permita conocer cuál es la tasa de sedimentación en este sitio y en el propio albardón. Para ello se prevé en el futuro llevar adelante muestreos continuos en la zona del albardón sin material cultural y realizar una batería de fechados OSL que permita obtener datos de la mencionada tasa. No obstante, a partir de los datos disponibles se puede plantear la existencia en el sitio de una sola ocupación temporalmente acotada, con mayor presencia de material cultural y nutrientes en la UEII y UEIII, que tienen a disminuir en el transcurso de esta última. En este contexto, es posible que el material haya sido desplazado por factores tafonómicos y por eso ambos fechados de UEIII son indiferenciables. Sin embargo, el primero (tope UE III) tiene una edad calibrada de 570-645 AD ( \pm 2 s; p. 0.9) y el segundo (base UE III) 575-652 $\mathrm{AD}$ ( $\pm 2 \mathrm{~s}$; p. 0.9), pero esto no quiere decir que sean contemporáneos, sino que representan 80 años de diferencia máxima.

Si bien es necesario extender estos análisis geoarqueológicos a la mayor cantidad de sitios elevados de la margen izquierda del río Uruguay, los datos generados en el presente programa de investigación indican la ausencia de estructuras construidas en dicha área. La opción inmediata de espacios con cotas más altas no inundables, como las que se desarrollan en los cordones arenosos 
y en las áreas de transición hacia la llanura de la margen izquierda, podría haber sido un eficaz estímulo para el no desarrollo de plataformas artificiales. Esto refuerza la hipótesis que relaciona su construcción con la carencia de espacios no anegables dentro del paisaje, como sucede en vastos sectores de diferentes áreas de la margen derecha del río Uruguay y Paraná inferior.

La construcción de montículos en tierra, ha sido considerada uno de los rasgos centrales de la emergencia de la complejidad social y de jerarquías políticas en las poblaciones del Holoceno Tardío del delta del Paraná (Bonomo et al. 2011a). Sin embargo, la existencia de poblaciones sincrónicas y socioculturalmente análogas en los litorales uruguayo y argentino, que se expresa arqueológicamente en similitudes a nivel de cultura material, patrón de subsistencia y asentamiento, la existencia de cementerios formales en áreas residenciales y la participación en redes de intercambio suprarregionales de objetos suntuarios manufacturados en moluscos marinos, rocas verdes y cobre (Araújo 1900; Boretto et al. 1974; Capdepont et al. 2010; de Freitas 1942; Díaz y Fornaro 1977; Fontana 1928; Gascue et al. 2016; 2019a y b; Maruca Sosa 1957) sugiere que la construcción de montículos en tierra entre los cazadores prehispánicos que habitaron las cuencas interconectadas Uruguay-Paraná durante el Holoceno tardío, estaría fuertemente influenciada por entornos topográficamente diferentes y no por desarrollos socioculturales disímiles.

Los suelos y sedimentos antrópicos constituyen ejemplos claros de gestión de los recursos y domesticación ambiental (Capra et al. 2005; Morgan y Heckenberger 2009). Esta gestión no debe vincularse exclusivamente con la generación de antrosoles neogenéticos y estos últimos tampoco deben ser considerados como indicadores inequívocos y excluyentes de la emergencia de la complejidad social. Las acciones humanas pasadas, tanto como las presentes, manipularon y alteraron significativamente la pedosfera, involucrando en estos procesos distintos grados de intencionalidad (Kern et al. 2017). En el sitio investigado es evidente que estas acciones, posiblemente vinculadas a la gestión cotidiana de los residuos domésticos, causaron efectos tanto físicos como bioquímicos que han dejado firmas distintivas y perdurables en el suelo incrementando notoriamente su fertilidad y estabilidad. El antrosol metagenético identificado en el sitio Isla del Vizcaíno 1 es un claro ejemplo de estas prácticas de transformación del suelo, que constituyen una verdadera herencia tecnológica que nuestros pueblos precolombinos nos legaron. Entender los procesos antrópicos que llevaron a la incorporación y, sobre todo, a la permanencia de altas concentraciones de nutrientes durante cientos de años en estos suelos arenosos, podría constituir un aporte significativo para un futuro sustentable.

\section{Agradecimientos}

A la Intendencia de Río Negro por su apoyo económico y logístico. Al personal de la isla del Vizcaíno que nos permitió acceder a los sitios y desarrollar las tareas de campo: Marcelo Urcade (administrador), Emilio Pérez (capataz) y en especial a Alejandro Lacerot y toda su familia (Matilde, «Dali», «Fer»y «Papo»). Queremos agradecer también a José «Pepe» Borrone quien nos facilitó la localización del sitio y a Caroline Borges, Frederik Poutet, Rafael Peroux, Mirena Atchugarry, Eduardo Keldjián, Agustina Fodrini y Dani Hernández por su colaboración en los trabajos de campo. Por último, pero no menos importante, a René Boretto por toda la información aportada, la cual contribuyó a enriquecer los resultados contenidos en este artículo. Cualquier error u omisión es responsabilidad de los autores.

\section{Nota}

1. Del latín Tumŭlus - Sepulcro levantado de la tierra (RAE 2019). 


\section{Referencias}

Acosta, A. y D. Loponte (2013). Complejidad social y estrategias de subsistencia de las poblaciones cazadorasrecolectoras del humedal del Paraná inferior, Cuadernos del Instituto Nacional de Antropología y Pensamiento Latinoamericano, Series Especiales, 1(4), 60-74.

Aparicio, F. (1937). Excavaciones en los paraderos del arroyo Leyes, Relaciones de la Sociedad Argentina de Antropología I, 7-20.

Araújo, O. (1900). Diccionario geográfico del Uruguay, Imprenta Artística, Montevideo.

Arredondo, H. (1927). Informe preliminar sobre la Arqueología de la boca del río Negro, Revista de la Sociedad Amigos de la Arqueología I, 7-45.

Arroyo-Kalin, M., E. Goes Neves y W. Woods (2009). Anthropogenic dark earths of the Central Amazon region: remarks on their evolution and polygenetic composition, en W. I. Woods, W. G. Teixeira, J. Lehmann, C. Steiner, A. Winkler Prins y L. Rebellato (eds.), Amazonian dark earths: Wim Sombroek's vision, 99-125, Springer, New York.

Bonomo, M., G. Politis y C. Gianotti (2011a). Montículos. Jerarquía social y horticultura en las sociedades indígenas del Delta del Río Paraná (Argentina), Latin American Antiquity 22, 297-333.

Bonomo, M., M. Colobig, E. Passeggi, A. F. Zucol, y M. Brea (2011b). Multidisciplinary studies at Cerro Tapera Vázquez site, Pre-Delta National Park, Argentina: The archaeological, sedimentological and paleobotanical evidence, Quaternary International 245(1), 48-61. https://doi.org/10.1016/j.quaint.2010.11.018

Bonomo, M., R. Costa Angrizani, E. Apolinaire y F. Noelli (2015). A model for the Guaraní expansion in the La Plata Basin and littoral zone of southern Brazil, Quaternary International 356, 54-73. https://doi. org/10.1016/j.quaint.2014.10.050

Bonomo, M., G. Politis y J. C. Castro (2010). Primeros resultados de las investigaciones arqueológicas en el delta superior del Paraná y su contribución al atlas arqueológico de la Provincia de Entre Ríos, Folia Histórica del Nordeste 18, 33-58. https://doi.org/10.7183/1045-6635.22.3.297

Boretto, R. (1968). Paraderos indígenas de las costas del río Uruguay en el Dpto. de Río Negro, Publicación del Museo Municipal de Historia Natural de Río Negro, s/d, 1-24, Río Negro, Uruguay.

Boretto, R. (1969). Hallazgo de un esqueleto en la Isla del Vizcaíno, Folleto de difusión cultural $N^{\circ} 2$, Museo Municipal de Historia Natural de Río Negro, Río Negro, Uruguay.

Boretto, R., R. Bernal, P. I. Schmitz, e I. Basile Becker (1973). Arqueología del Departamento de Río Negro. Esquema Tentativo de una Secuencia Cronológica para Sitios del Río Uruguay y Río Negro, I Congreso Nacional de Arqueología II Encuentro de Arqueología del Interior, sin paginar, Fray Bentos, Uruguay.

Boretto, R., R. Bernal, P. I. Schmitz, e I. Basile Becker (1974). Arqueología del Departamento de Río Negro. Esquema Tentativo de una Secuencia Cronológica para Sitios del río Uruguay y río Negro. Resultados parciales a Diciembre de 1973, II Congreso Nacional de Arqueología III Encuentro de Arqueología del Interior, sin paginar, Fray Bentos, Uruguay.

Bortolotto, N. (2018). Análisis tecno-morfológico de piedras con hoyuelos recuperadas en el sitio La YeguadaNuevo Berlín-Departamento de Río Negro-Uruguay, tesina de licenciatura, Universidad de la Republica, Uruguay.

Bortolotto, N., M. Fleitas y A. Gascue (2015). Conservación Preventiva de la colección arqueológica del ex Museo Municipal de Historia Natural de Río Negro-Uruguay, Cuadernos del Instituto Nacional de Antropología y Pensamiento Latinoamericano - Series Especiales 2(3), 9-24.

Bossi, J., L. Ferrando, J. Montaña, N. Campal, H. Morales, F. Gancio, A. Schipilov, G. Pińeyro y P. Sprechman (1998). EOCARTA, Carta geológica del Uruguay - 1:500.000 Versión 1.01, Geoeditores SRL.

Bracco, R., L. Cabrera, y J. M. López (2000). La prehistoria de las tierras bajas de la cuenca de la laguna Merín, en A. Durán y R. Bracco (eds.), Arqueología de las Tierras Bajas, 13-38, Ministerio de Educación y Cultura, Comisión Nacional de Arqueología, Montevideo, Uruguay.

Bray, R. y L. Kurtz (1945). Determination of total, organic and available forms of phosphorus in soils, Soil Sci. 59, 39-45.

Burkart, R., N., Bárbaro, R. Sánchez y D. Gómez (1999). Eco-regiones de la Argentina, Presidencia de la Nación, Secretaría de Recursos Naturales y Desarrollo Sustentable, Administración de Parques Nacionales, Buenos Aires.

Cabrera, Á. y A. Willink (1980). Biogeografía de América Latina, Serie Biología Monografía (3), Organización de Estados Americanos (AEO). 
Capdepont, I., H. Inda y L. del Puerto (2010). Patrones de asentamiento de sociedades alfareras del bajo río Uruguay, en: G. Cocco y M. R. Fuillet Terzaghi (eds.), Arqueología de cazadores recolectores en la cuenca del Plata, 87-99, Centro de Estudios Hispanoamericanos, Santa Fe.

Capra, G. F., A. Ganca, E. Grilli, S. Vacca y A. Buondonno (2015). A review on anthropogenic soils from a worldwide perspective, Journal Soils Sediments 15, 1602-1618. https://doi.org/10.1007/s11368-015-1110-x

Carver, R. (1971). Procedures in sedimentary petrology, Wiley-Interscience, New York.

Castińeira, C. y G. Piñeiro (2000). Análisis estadístico textural para el estudio de las columnas estratigráficas de las excavaciones I y II del Bañado de los Indios, en: A. Durán y R. Bracco (eds.), Arqueología de las Tierras Bajas, 467-478, Ministerio de Educación y Cultura, Comisión Nacional de Arqueología, Montevideo.

Castińeira, C., A., Blasi, G. Politis, M. Bonomo, L. del Puerto, R. Huarte, J. Carbonari, F. Mari y F. GarcíaRodríguez (2013). The origin and construction of pre-Hispanic mounds in the Upper Delta of the Paraná River (Argentina) Archaeol Anthropol Sci. 5, 37-57. https://doi.org/10.1007/s12520-012-0107-2

Castiñeira, C., A. Blasi, M. Bonomo, G. Politis y E. Apolinaire (2014). Modificación antrópica del paisaje durante el Holoceno tardío: las construcciones monticulares en el delta superior del río Paraná, Revista de la Asociación Geológica Argentina 71(1), 33-47.

Certini, G. y R. Scalenghe (2011). Anthropogenic soils are the golden spikes for the Anthropocene, The Holocene 21(8) 1269-1274. https://doi.org/10.1177/0959683611408454

Ceruti, C. (2003). Entidades culturales presentes en la cuenca del Paraná Medio (margen entrerriana), Mundo de Antes 3, 111-135.

Ceruti, C., O. Fontana, L. López y C. Vesco (1980). Arroyo Arenal 4: un hallazgo arqueológico poco común, Municipalidad de La Paz, La Paz.

Ceruti, C. y M. González (2007). Modos de vida vinculados con ambientes acuáticos del Nordeste y Pampa Bonaerense de Argentina, Relaciones de la Sociedad Argentina de Antropología 33, 101-140.

Céspedes Payret, C. (2007). Dinámica de la materia orgánica y de algunos parámetros fisicoquímicos en molisoles, en la conversión de una pradera a cultivo forestal en la región de Piedras Coloradas-Algorta (Uruguay), tesis de maestría, Institut National Polytechnique de Toulouse.

Chalar, G., M. Gerhard, M. González-Piana y D. Fabián (2014). Hidroquímica y eutrofización en tres embalses subtropicales en cadena, en: J.E. Marcovecchio, S.E. Botté y R. H. Freije (eds.), Procesos geoquimicos superficiales en Sudamérica, 121-148, Nueva Graficesa, Salamanca.

CONEAT (1979). Grupos de Suelos. Indices de Productividad. Montevideo, Comisión Nacional de Estudio Agroeconómico de la Tierra, Ministerio de Agricultura y Pesca, Uruguay.

Dazzi, C. y G. Lo Papa (2015). Taxonomic and environmental implication of pedotechnique in large scale farming, International Soil and Water Conservation Research 4, 137-141. https://doi.org/10.1016/j.iswcr.2016.01.001

De Freitas, C. (1942). Alfarería del delta del río Negro (paradero La Blanqueada), Revista Histórica XIII (38-39), 363-418.

De Freitas, C. (1953). Alfarería indígena. Hallazgos de trozos de vasijas construidas por los primitivos habitantes del litoral uruguayo, Revista de la Sociedad Amigos de la Arqueología XII, 40-49.

Díaz, A., A. Bosch, M. Moreno, J. Femenías y O. Becerra (1974). Los materiales arqueológicos del sitio Colonia Concordia Dpto. de Soriano. República Oriental del Uruguay, III Congreso Nacional de Arqueología IV Encuentro de Arqueología del Litoral CEA, sin paginar, Fray Bentos.

Díaz, A. y M. Fornaro (1977). Intento de sistematización de las modalidades alfareras del litoral uruguayo, $V$ Encuentro de arqueología del Litoral, 165-174, MEC.

Durán, A. (1990). Observaciones sobre los suelos del sitio arqueológico de San Miguel. Ms.

Farías, M. (2005). El Guaraní arqueológico meridional: entre el axioma y la heterodoxia, tesis de doctorado, PUCRS, Porto Alegre.

Figueira, J. H. (1892). Los primitivos habitantes del Uruguay. Uruguay en la exposición histórica de Madrid, Imprenta Artística Dornaleche y Reyes, Montevideo.

Figueira, J. H. (1930). Memoria de la excursión científica a Nueva Palmira, Revista Sociedad Amigos de la Arqueología Tomo II: 119-181, Montevideo.

Folk, R. L. y W. C. Ward (1957). Brazos River bar (Texas); a study in the significance of grain size parameters, J. Sediment 27 (1), 3-26. https://doi.org/10.1306/74D70646-2B21-11D7-8648000102C1865D

Folk, R. L., P. B. Andrews y D. W. Lewis (1970). Detrital sedimentary rock classification and nomenclature for use in New Zealand, New Zeal, J. Geol. Geophys 13(4), 937-968. https://doi.org/10.1080/00288306.1970. 10418211

Fontana, M. (1928). Informe sobre la exploración de un túmulo indígena en Punta Chaparro, Revista de la Sociedad Amigos de la Arqueología II, 331-349. 
Frenguelli, J. y F. Aparicio (1923). Los Paraderos de la Margen Derecha del Río Malabrigo (Departamento de Reconquista, Prov. Santa Fe), Anales de la Facultad de Ciencias de la Educación I, 7-112.

Gasche, H. y O. Tunca (1983). Guide to strratigraphic classification and terminology; Definitions and principles, Journal of Field Archaeology 10, 325-335. https://doi.org/10.1179/009346983791504318

Gascue, A. (2009). Análisis y clasificación de los enterramientos humanos prehistóricos del litoral uruguayo y noreste argentino, en: J. M. López Mazz y A. Gascue (eds.), Arqueología prehistórica uruguaya en el siglo XXI, 197-215, Biblioteca Nacional/Facultad de Humanidades y Ciencias de la Educación, Montevideo.

Gascue, A. y N. Bortolotto (2016). La ocupación guaraní en la margen oriental del bajo río Uruguay: tecnología cerámica y lítica del sitio Punta Negra Este, Serie Monográfica y Didáctica 54, 487-495.

Gascue, A., D. Loponte, F. Moreno, N. Bortolotto, X. Rodriguez, G. Figueiro, F. Teixeira de Mello y A. Acosta (2016). Tecnología, subsistencia y cronología del sitio El Cerro, Departamento de Río Negro, Uruguay, Anuario de Arqueología 8, 113-140.

Gascue, A., N. Bortolotto, D. Loponte, A. Acosta, C. Borges, M. Fleitas y A. Fodrini (2019a). Contextos geomorfológicos y tecno-económicos del registro arqueológico del bajo río Uruguay (margen izquierda). Resultados preliminares de nuevas prospecciones, Revista Arqueología 25(3), 87-117.

Gascue, A., F. Scarabino, N. Bortolotto, C. Clavijo, I. Capdepont (2019b). El rol de los moluscos en las poblaciones prehispánicas de Uruguay, Comechingonia Revista de Arqueología 23(1), 115-152.

Gaspary, F. (1950). Investigaciones Arqueológicas y Antropológicas en un Cerrito de la Isla Los Marinos, Provincia de Entre Rios. Córdoba, Instituto de Arqueología Lingüística y Folklore «Dr. Pablo Cabrera», XXIII, Universidad Nacional de Córdoba, Córdoba.

González, A. R. (1947). Investigaciones arqueológicas en las nacientes del Paraná Pavón, Universidad Nacional de Córdoba, Córdoba.

Greslebin, H. (1931). La estructura de los túmulos indígenas prehispánicos del departamento de Gualeguaychú (Provincia de Entre Ríos, R. Argentina), Revista Sociedad Amigos de la Arqueología Tomo V, 5-51.

Hammer, Ø., D. Harper yP. D. Ryan (2001). PAST: Paleontological statistics software package for education and data analysis, Palaeontologia Electronica 4(1).

Harris, E. (1989). Principles of archaeological stratigraphy, Academic Press, London.

Heiri, O., A.Lotter y G. Lemcke (2001). Loss on ignition as a method for estimating organic and carbonate content: reproducibility and comparability of the results, Journal of Paleolimnology 25, 101-110.

Howard, J. (2017). Anthropogenic Soils, Progress in Soil Science, Springer, Cham.

Howard, J., K. Ryzewski, B. Dubay y T. Killion (2015). Artifact preservation and post-depositional site-formation processes in an urban setting: a geoarchaeological study of a 19th century neighborhood in Detroit, Michigan, Journal of Archaeologial Science 53, 178-189. https://doi.org/10.1016/j.jas.2014.10.004

Howard, J. y K. Orlicki (2015). Effects of anthropogenic particles on the chemical and geophysical properties of urban soils, Soil Science 180, 154-166. https://doi.org/10.1097/SS.0000000000000122

Howard, J. y K. Orlicki (2016). Composition, micromorphology and distribution of microartifacts in anthropogenic soils, Catena 138, 38-51.

Kern, D. y N. Kämpf (1989). Antigos assentamentos indígenas na formação de solos com terra preta arqueológica na região de Oriximina, Para, Revista Brasileira de Ciência do Solo 13(2), 219-225.

Kern, D., H. Pinto Lima, J. Amorim da Costa, H. Veras de Lima, A. Browne Ribeiro, B. M. Moraes y N. Kämpf (2017). Terras pretas: Approaches to formation processes in a new paradigm, Geoarchaeology 32, 694-706. https://doi.org/10.1002/gea.21647

Lafón, C. R. (1971). Introducción a la Arqueología del Nordeste Argentino, Relaciones de la Sociedad Argentina de Antropología, Nueva Serie 2(5), 119-152.

Lima, H., C. Schaefer, J. Mello, R. Gilkes y J. Ker (2002). Pedogenesis and pre-Columbian land use of «Terra Preta Anthrosols» (Indian black earth) of Western Amazonia, Geoderma 110, 1-17.

Lista, R. (1878).Les cimetières et paraderos minuanes de la province de Entre-Rios, Revue d'Anthropologie 1, $365-368$

López Mazz, J. M. (1992). Aproximación a la génesis y desarrollo de los cerritos de la zona de San Miguel (Depto. de Rocha), Ediciones del Quinto Centenario, Universidad de la República 1, 60-80, Montevideo.

López Mazz, J. M. y R. M. López Cabral (2020). The presence of Guaraní groups in the current Uruguayan territory, Journal of Anthropological Archaeology 59, 1-10.

Loponte, D., A. Acosta y J. Musali (2006). Complexity among hunter-gatherers from gion, South America, en: C. Grier, J. Kim y J. Uchiyama (eds.), Beyond affluent oragers: Rethinking hunter-gatherer complexity, 106-125, Oxbow Books, Oxford. 
Loponte, D. (2008). Arqueología del humedal del Paraná Inferior (Bajíos Ribereńos Meridionales), tesis de doctorado, Instituto Nacional de Antropología y Pensamiento Latinoamericano, Buenos Aires.

Loponte, D. y A. Acosta (2016). Los contextos Goya-Malabrigo del noreste argentino, Cadernos do Ceom 45(29), 125-187. https://doi.org/10.22562/2016.45.06

Loponte, D., A. Acosta y P. Tchilinguirián (2016b). Estructuras «monticulares», unidades arqueológicas y falsas premisas en la arqueología del noreste argentino, Anuario De Arqueología 8(8), 45-78.

Loponte, D., F. Ottalagano, A. Acosta, N. Bortolotto, A. Gascue, D. Viglioco y R. Boretto (2016a). Avances en la Arqueología del bajo río Uruguay: el sitio La Yeguada, departamento de Río Negro (Uruguay), Tessituras $1(4), 8-52$.

Lothrop, S. (1932). Indians of the Paraná Delta, Argentina, Annals of the New York Academy of Science 32, 77-232.

Maeso Tognochi, C. (1977). Investigaciones arqueológicas, Imprenta Don Bosco, Montevideo.

Maruca Sosa, R. (1957). La nación charrúa, Editorial Letras, Montevideo.

Mazza, B., A. Acosta, A. Guarido, N. Buc y D. Loponte (2018). Anthropogenic modifications to archaeological human bones from the lower Paraná River basin (Argentina), Journal of Archaeological Science: Reports 20, 647-661. https://doi.org/10.1016/j.jasrep.2018.06.013

Morgan, S. y J. Heckenberger (2009). Amerindian Anthrosols: Amazonian Dark Earth Formation in the Upper Xingu, en: W. Woods, W Teixeira, J. Lehmann, C. Steiner, A. Winkler Prins y L. Rebellato (eds.), Amazonian dark earths: Wim Sombroek's vision, 163-191, Springer-Verlag, Berlin.

Nóbile, J., C. Ceruti y S. Cornero (1999). Investigaciones arqueológicas en el área de Alejandra Depto. de San Javier, Pcia. de Santa Fe, Actas del XII Congreso Nacional de Arqueología Argentina III, 389-393.

Noelli, F. (2014). O espaço dos Guaraní: A construção do mapa arqueológico no Brasil, Paraguai, Argentina e Uruguay, en: R. Guedes Milheira y G. Peretti Wagner (eds.), Arqueología Guaraní no litoral Sul do Brasil, 187-288, Annris, Curitiba.

Ottalagano, F. (2010). Decoración experimental de cerámica aplicada al estudio de las técnicas incisas del área del Paraná, Intersecciones en Antropología 11, 237-247.

Ottalagano, F. (2013). Aves simbólicas, estilo e identidad en la arqueología del gran rio sudamericano: Un estudio contextual del arte cerámico de las sociedades prehispánicas de la cuenca del Paraná Medio, Arqueología de la Cuenca del Plata. Serie Monográfica, Instituto Nacional de Antropología y Pensamiento Latinoamericano, Buenos Aires

Outes, F. (1912). Cráneos indígenas del departamento de Gualeguaychú (Provincia de Entre Ríos), Anales de la Sociedad Cientifica Argentina, LXXIII, 6-35.

Palacios, J. (2002). Aspectos ambientales del río Uruguay. http://sanantonio.unorte.edu.uy/proyectoscomplementarios/pdf/fas1/RelevamientoMedioAmbiental/MACUG1.pdf, accedido el 10 de mayo 2018.

Pettijohn, F. P., P.E. Potter y R. Siever (1973). Sand and sandstones, Springer/Verlag, New York/Heidelberg/Berlin. Pi Hugarte, R. (1969). El Uruguay indígena, Nuestra Tierra 1, 1-68.

Politis, G., M. Bonomo, C. Castińeira, y A. Blasi (2011). Archaeology of the Upper Delta of the Paraná River (Argentina): Mound construction and anthropic landscapes in the Los Tres Cerros locality, Quaternary International 245(1), 74-88. https://doi.org/10.1016/j.quaint.2011.02.007

Preciozzi Porta, F., J. Spoturno, P., Rossi y W. Heinzen (1985). Memoria explicativa de la Carta Geológica del Uruguay escala 1.500.000, Ministerio de Industria Energética y Minería, Dirección Nacional de Minería y Geología, Montevideo.

R Core Team (2017). R: A language and environment for statistical computing, R Foundation for Statistical Computing, Vienna, Austria. https://www.R-project.org/

Schmidt, M. J. y M. J. Heckenberger (2009). Amerindian Anthrosols: Amazonian Dark Earth Formation in the Upper Xingu, en: W. I. Woods, W.G. Teixeira, J. Lehmann, C. Steiner, A. Winkler Prins y L. Rebellato (eds.), Amazonian dark earths: Wim Sombroek's vision, 163-191, Springer, New York.

Serrano, A. (1936). Etnografía de la Antigua Provincia del Uruguay, Talleres Gráficos «Melchior», Paraná.

Serrano, A. (1972). Lineas fundamentales de la arqueología del litoral (Una tentativa de periodización), Instituto de Antropología, Universidad Nacional de Córdoba, Córdoba.

Soil Survey Staff (2014). Keys to soil taxonomy, U.S. Department of Agriculture, Natural Resources Conservation Service.

Sombroek, W. (1966). Amazon soils: A reconnaissance of the soils of the Brazilian Amazon region, Centre for Agricultural Publications and Documentation, Wageningen.

Sombroek, W., D. Kern, T. Rodrigues, M. da Silva Cravo, T. J. Cunha, W. I. Woods y B. Glaser (2002). Terra Preta and Terra Mulata: pre-Columbian Amazon kitchen middens and agricultural fields, their sustainability and their replication, 17th World Congress of Soil Science, s/p. Bangkok. 
Stein. J.K. (1990). Archaeological stratigraphy, en: N.P. Lasca y J. Donahue (eds.), Archaeological geology of North America, Geological Society of America Centennial Special Volume 4, 513-523.

Teisseire, A. (1927). Expedición a los departamentos de Colonia y Soriano, Revista de la Sociedad Amigos de la Arqueología I, 47-61.

Torres L. (1911). Los primitivos habitantes del delta del Paraná, Universidad Nacional de La Plata.

Tuya de Maeso, L. (1980). Consideraciones sobre la cerámica de los yacimientos arqueológicos investigados en los departamentos de Colonia, Soriano y Río Negro. Decoración-expresiones zoomorfas, Talleres Don Bosco, Montevideo.

Wentworth, C. (1922). A scale of grade and class terms for clastic sediments, Journal of Geology 30 (5), 377-392. https://doi.org/10.1086/622910

Recibido: 08/07/2020

Aprobado: 25/11/2020 